\title{
The acyl-glucuronide metabolite of ibuprofen has analgesic and anti- inflammatory effects via the TRPA1 channel
} \author{
Romina Nassini ${ }^{a, *}$ \\ ${ }^{a}$ Department of Health Sciences, Section of Clinical Pharmacology and Oncology, University of Florence, Florence, Italy \\ ${ }^{\mathrm{b}}$ Department of Pharmacy, University of Pisa, Pisa, Italy \\ ${ }^{\mathrm{c}}$ Department of Chemical and Pharmaceutical Sciences, University of Ferrara, Ferrara, Italy \\ ${ }^{\mathrm{d}}$ Department of Corporate Drug Development, Chiesi Farmaceutici SpA, Parma, Italy \\ ${ }^{\mathrm{e}}$ Laboratory of Pain and Analgesia, Beritashvili Center for Experimental Biomedicine, Tbilisi, Georgia
}

Francesco De Logu ${ }^{\mathrm{a}}$, Simone Li Puma ${ }^{\mathrm{a}}$, Lorenzo Landini ${ }^{\mathrm{a}}$, Tiziano Tuccinardi ${ }^{\mathrm{b}}$, Giulio Poli ${ }^{\mathrm{b}}$, Delia Preti $^{\mathrm{c}}$, Gaetano De Siena ${ }^{\mathrm{a}}$, Riccardo Patacchini ${ }^{\mathrm{d}}$, Merab G. Tsagareli ${ }^{\mathrm{e}}$, Pierangelo Geppetti ${ }^{\mathrm{a}}$,

A R T I C L E IN F O

\section{Keywords:}

TRPA1

Ibuprofen-acyl glucuronide

Inflammatory pain

Inflammation

\begin{abstract}
A B S T R A C T
Ibuprofen is a widely used non-steroidal anti-inflammatory drug (NSAID) that exerts analgesic and anti-inflammatory actions. The transient receptor potential ankyrin 1 (TRPA1) channel, expressed primarily in nociceptors, mediates the action of proalgesic and inflammatory agents. Ibuprofen metabolism yields the reactive compound, ibuprofen-acyl glucuronide, which, like other TRPA1 ligands, covalently interacts with macromolecules. To explore whether ibuprofen-acyl glucuronide contributes to the ibuprofen analgesic and anti-inflammatory actions by targeting TRPA1, we used in vitro tools (TRPA1-expressing human and rodent cells) and in vivo mouse models of inflammatory pain. Ibuprofen-acyl glucuronide, but not ibuprofen, inhibited calcium responses evoked by reactive TRPA1 agonists, including allyl isothiocyanate (AITC), in cells expressing the recombinant and native human channel and in cultured rat primary sensory neurons. Responses by the nonreactive agonist, menthol, in a mutant human TRPA1 lacking key cysteine-lysine residues, were not affected. In addition, molecular modeling studies evaluating the covalent interaction of ibuprofen-acyl glucuronide with TRPA1 suggested the key cysteine residue C621 as a probable alkylation site for the ligand. Local administration of ibuprofen-acyl glucuronide, but not ibuprofen, in the mouse hind paw attenuated nociception by AITC and other TRPA1 agonists and the early nociceptive response (phase I) to formalin. Systemic ibuprofen-acyl glucuronide and ibuprofen, but not indomethacin, reduced phase I of the formalin response. Carrageenan-evoked allodynia in mice was reduced by local ibuprofen-acyl glucuronide, but not by ibuprofen, whereas both drugs attenuated $\mathrm{PGE}_{2}$ levels. Ibuprofen-acyl glucuronide, but not ibuprofen, inhibited the release of IL-8 evoked by AITC from cultured bronchial epithelial cells. The reactive ibuprofen metabolite selectively antagonizes TRPA1, suggesting that this novel action of ibuprofen-acyl glucuronide might contribute to the analgesic and anti-inflammatory activities of the parent drug.
\end{abstract}

\section{Introduction}

Ibuprofen, the first approved member of propionic acid derivatives, is a classical non-steroidal anti-inflammatory drug (NSAID) widely used for its analgesic and anti-inflammatory properties [1,2]. Ibuprofen is indicated to relieve inflammation and several types of pain, including headache, muscular pain, toothache, backache, and dysmenorrhea [2]. Therapeutic effects of ibuprofen are attributed to inhibition of prostanoid synthesis by a non-selective, reversible inhibition of both cyclooxygenase 1 (COX1) and 2 (COX2) [3,4].

\footnotetext{
Abbreviations: AITC, allyl isothiocyanate; IAG, ibuprofen-acyl glucuronide; ANOVA, analysis of variance; COX, cyclooxygenase; DRG, dorsal root ganglia; DMEM,

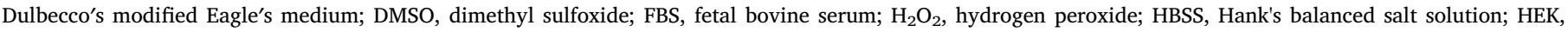

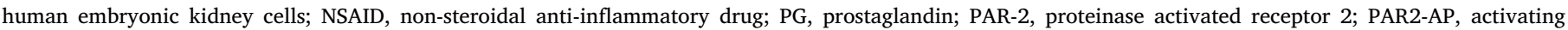

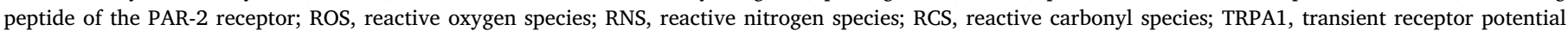
ankyrin 1; TRPV1, transient receptor potential vanilloid 1; TRPV4, transient receptor potential vanilloid 4; $\mathrm{ZnCl}_{2}$, zinc chloride

* Corresponding author at: Department of Health Sciences, University of Florence, Viale Pieraccini 6, 50139 Florence, Italy.

E-mail address: romina.nassini@unifi.it (R. Nassini).
} 
The transient receptor potential ankyrin 1 (TRPA1), coexpressed with the TRP vanilloid 1 (TRPV1) in a subpopulation of primary sensory neurons, is activated by exogenous compounds, such as allyl isothiocyanate (AITC) and cinnamaldehyde [5], and by an unprecedented series of reactive oxidative, nitrogen and carbonylative species (ROS, RNS and RCS, respectively), including hydrogen peroxide $\left(\mathrm{H}_{2} \mathrm{O}_{2}\right)$ and the electrophilic $\alpha, \beta$-unsaturated aldehydes, 4-hydroxynonenal and acrolein [6-10]. Such compounds, via Michael addition or oxidation reactions, covalently bind specific cysteine/lysine residues of the cytoplasmic amino-terminus [11,12], thus gating the channel. TRPA1 has been proposed as a major pain transducer [13-15], because of its implication in models of both inflammatory pain, including those evoked by formalin [16] and carrageenan [17,18], and neuropathic pain, such as those induced by nerve injury [19-21], or anticancer drugs [22,23]. Clinical interest for the therapeutic potential of TRPA1 blockade is underlined by current clinical trials with TRPA1 antagonists [24]. Expression of TRPA1 is not limited to primary sensory neurons, as its presence and functions have been documented in a variety of nonneuronal cells, including some cells of the airway tissues, where its activation evokes the release of proinflammatory cytokines, such as interleukin-8 [25-27].

Ibuprofen is almost completely metabolized, via an oxidative reaction to the inactive metabolites, carboxy-ibuprofen and 2-hydroxyibuprofen, which are both eliminated in the urine [28,29]. However, $10-15 \%$ of ibuprofen is glucuronidated to ibuprofen-acyl glucuronide [28]. Plasma levels of ibuprofen and ibuprofen-acyl glucuronide have been assessed in patients receiving long-term administration of oral doses of $600 / 800 \mathrm{mg}$ ibuprofen. The ibuprofen and ibuprofen-acyl glucuronide ratio was $~ 30$ to 1 , [30]. Although glucuronidation is generally considered a detoxification pathway, acyl glucuronides undergo molecular rearrangement to reactive metabolites, which may covalently bind various macromolecules [30,31]. Therefore, we investigated whether ibuprofen-acyl glucuronide antagonizes TRPA1 and, via this mechanism, contributes to the analgesic and anti-inflammatory actions of ibuprofen. We found that ibuprofen-acyl glucuronide, but not ibuprofen, attenuates excitatory and pro-inflammatory responses in TRPA1-expressing cells in vitro and proalgesic responses in vivo elicited by reactive agonists of the channel. Ibuprofen-acyl glucuronide also selectively attenuated the TRPA1-dependent component of the proalgesic responses evoked in vivo by formalin or carrageenan, thus underlying the hypothesis that TRPA1 targeting by ibuprofen-acyl glucuronide contributes to both analgesic and anti-inflammatory effects of ibuprofen.

\section{Materials and methods}

\subsection{Animals}

In vivo experiments and tissue collection were carried out according to European Union (EU) guidelines and Italian legislation (DLgs 26/ 2014, EU Directive application 2010/63/EU) for animal care procedures, and under the University of Florence research permit \#194/ 2015-PR. C57BL/6 J mice (male, 20-22 g, 6 weeks; Envigo, Milan, Italy); TRPA1-deficient (Trpa1 ${ }^{-/-}$) mice (25-30 g, 5-8 weeks) [32] or Sprague-Dawley rats (male, 75-100 g, Envigo, Milan, Italy) were used. Animals were housed in a temperature- and humidity-controlled vivarium (12-hour dark/light cycle, free access to food and water). Animal studies were reported in compliance with the ARRIVE guidelines [33].

Group size of $\mathrm{n}=6$ animals for behavioral experiments were determined by sample size estimation using G*Power (v3.1) [34] to detect size effect in a post-hoc test with type 1 and 2 error rates of 5 and $20 \%$, respectively. Allocation concealment was performed using a randomization procedure (http://www.randomizer.org/). Experiments were done in a quiet, temperature-controlled $\left(20-22^{\circ} \mathrm{C}\right)$ room between 9 a.m. and 5 p.m. and were performed by an operator blinded to drug treatment. Animals were euthanized with inhaled $\mathrm{CO}_{2}$ plus $10-50 \% \mathrm{O}_{2}$. For the in vitro experiments we used a total of 10 rats and 42 mice.

\subsection{Reagents and cells}

HC-030031 [2-(1,3-dimethyl-2,6-dioxo-1,2,3,6-tetrahydro-7Hpurin-7-yl)-N-(4-isopropylphenyl) acetamide] was synthesized as previously described [35]. If not otherwise indicated, reagents were obtained from Sigma-Aldrich (Milan, Italy). Human embryonic kidney 293 (hHEK293, American Type Culture Collection; ATCC ${ }^{\oplus}$ CRL-1573 ${ }^{\mathrm{TM}}$ ) cells, HEK293 cells stably transfected with cDNA for human TRPA1 (hTRPA1-HEK293), or with the cDNA for human TRPV1 (hTRPV1HEK293), or with the cDNA for human TRPV4 (hTRPV4-HEK293), or with cDNA for both human TRPA1 and human TRPV1 (hTRPA1/V1HEK293) channels, were cultured as previously described [36-39]. hHEK293 cells were transiently transfected with the cDNAs $(1 \mu \mathrm{g})$ codifying for wild type (Wt) (hTRPA1-HEK293) or mutant human TRPA1 (C619S, C639S, C663S, K708Q; 3C/K-Q hTRPA1-HEK293) [11] using the jetPRIME transfection reagent (Poliyplus-transfection ${ }^{\circledR}$ SA, Thermo Scientific, Monza, Milan), according to the manufacturer's protocol.

Human embryonic lung fibroblasts (IMR90; ATCC ${ }^{\circledast}$ CCL-186 ${ }^{\mathrm{TM}}$ ) were used as a model of human cells constitutively expressing the TRPA1 channel and were cultured in Dulbecco's Modified Eagle's Medium (DMEM) supplemented with 10\% fetal bovine serum (FBS), $2 \mathrm{mM}$ glutamine, $100 \mathrm{U}$ penicillin and $100 \mu \mathrm{g} / \mathrm{ml}$ streptomycin, according to the manufacturer's instructions. Normal human bronchial epithelial cells (NHBE; Lonza Group Ltd, Basel, Switzerland) were cultured in NHBE growth medium, according to the manufacturer's instructions. All cells were cultured in an atmosphere of $95 \%$ air and $5 \% \mathrm{CO}_{2}$ at $37^{\circ} \mathrm{C}$. For all cell lines, the cells were used when received without further authentication.

Rodent primary sensory neurons were isolated from dorsal root ganglia (DRGs) taken from Sprague-Dawley rats and cultured as previously described [35]. Briefly, ganglia were bilaterally excised under a dissection microscope and transferred in Hank's balanced salt solution (HBSS) containing $2 \mathrm{mg} / \mathrm{ml}$ collagenase type $1 \mathrm{~A}$ and $1 \mathrm{mg} / \mathrm{ml}$ trypsin, for enzymatic digestion $\left(30 \mathrm{~min}, 37^{\circ} \mathrm{C}\right.$ ). Ganglia were then transferred to warmed DMEM containing $10 \%$ FBS, $10 \%$ horse serum, $2 \mathrm{mM} \mathrm{L-}$ glutamine, $100 \mathrm{U} / \mathrm{ml}$ penicillin and $100 \mathrm{mg} / \mathrm{ml}$ streptomycin and dissociated in single cells by several passages through a series of syringe needles (23-25 G). Medium and ganglia cells were filtered to remove debris and centrifuged. The pellet was resuspended in DMEM with added $100 \mathrm{ng} / \mathrm{ml}$ mouse-nerve growth factor and $2.5 \mathrm{mM}$ cytosine-b-Darabino-furanoside free base. Neurons were then plated on $25 \mathrm{~mm}$ diameter glass coverslips coated with poly-L-lysine $(8.3 \mu \mathrm{M})$ and laminin $(5 \mu \mathrm{M})$. DRG neurons were cultured for 3-4 days before being used for calcium imaging experiments.

\subsection{Calcium imaging assay}

Single cell intracellular calcium was measured in untransfected and in hTRPA1-HEK293, hTRPV1-HEK293, hTRPV4-HEK293, hTRPA1/V1HEK293, 3C/K-Q hTRPA1-HEK293 cells, IMR90 fibroblasts, NHBE cells, or in rat DRG neurons. Plated cells were loaded with $5 \mu \mathrm{M}$ Fura2 AM-ester (Alexis Biochemicals; Lausen, Switzerland) added to the buffer solution $\left(37^{\circ} \mathrm{C}\right.$ ) containing the following (in $\mathrm{mM}$ ): $2 \mathrm{CaCl}_{2} ; 5.4$ $\mathrm{KCl} ; 0.4 \mathrm{MgSO}_{4} ; 135 \mathrm{NaCl} ; 10$-glucose; 10 HEPES and $0.1 \%$ bovine serum albumin at $\mathrm{pH}$ 7.4. After loading ( $40 \mathrm{~min}$ ), cells were washed and transferred to a chamber on the stage of an Olympus IX81 microscope for recording. Cells were excited alternatively at 340 and $380 \mathrm{~nm}$ and recorded with a dynamic image analysis system (XCellence Imaging software; Olympus srl, Milan, Italy). To evoke a TRPA1-dependent calcium response, cells and neurons were challenged with AITC $(1-1000 \mu \mathrm{M})$, acrolein $(10 \mu \mathrm{M})$, hydrogen peroxide $\left(\mathrm{H}_{2} \mathrm{O}_{2}, 500 \mu \mathrm{M}\right)$, icilin $(30 \mu \mathrm{M})$, zinc chloride $\left(\mathrm{ZnCl}_{2}, 1 \mu \mathrm{M}\right)$ or menthol $(100 \mu \mathrm{M})$. Buffer solution containing $1 \%$ dimethyl sulfoxide (DMSO) was used as vehicle. 
The selective TRPV1 agonist, capsaicin $(0.1 \mu \mathrm{M})$, was used in hTRPV1HEK293, in hTRPA1/V1-HEK293 and, to identify TRPV1-expressing neurons and $\mathrm{KCl}(50 \mathrm{mM})$, to identify the entire neuronal population [40]. The selective TRPV4 agonist, GSK1016790 A (0.1 $\mu \mathrm{M})$, was used in hTRPV4-HEK293 cells. hTRPA1-HEK293, hTRPV1-HEK293, hTRPV4-HEK293, hTRPA1/V1-HEK293, IMR90 fibroblasts and NHBE cells were challenged with the activating peptide (AP) of the human proteinase activated receptor 2 (hPAR2) (hPAR2-AP, SLIGKV-NH $\mathrm{N}_{2}, 100$ $\mu \mathrm{M})$.

Cells or neurons were pre-exposed $(10 \mathrm{~min})$ to ibuprofen-acyl glucuronide $(1-300 \mu \mathrm{M})$, ibuprofen $(100 \mu \mathrm{M})$, HC-030031 $(0.1-30 \mu \mathrm{M})$, capsazepine $(10 \mu \mathrm{M})$, HC-067047 $(10 \mu \mathrm{M})$ or vehicle $(0.3 \%$ DMSO) before the addition of the TRPA1, TRPV1 or TRPV4 agonists. Results were expressed as the percentage of the increase in $\mathrm{R}_{340 / 380}$ over baseline, normalized to the maximum effect induced by ionomycin ( 5 $\mu \mathrm{M}$ ) added at the end of each experiment (\% Change in $\mathrm{R}_{340 / 380}$ ); or as the percentage of the inhibitory effect on the calcium response evoked by AITC (\% AITC response) for constructing the concentration-response curves in the presence of ibuprofen-acyl glucuronide.

\subsection{Behavioral experiments}

\subsubsection{Treatment protocols}

C57BL/ $6 \mathrm{~J}$ mice were injected in the plantar surface of the hind paw (intraplantar, i.pl., $20 \mu \mathrm{l} /$ paw) with a mixture of AITC, acrolein or $\mathrm{ZnCl}_{2}$ (all, $10 \mathrm{nmol}$ ) [40] and ibuprofen-acyl glucuronide $(0.3-300 \mathrm{nmol})$ or HC-030031 (0.3-300 nmol) or ibuprofen (300 nmol), or capsaicin $(1 \mathrm{nmol})$ and capsazepine $(300 \mathrm{nmol})$, or hypotonic solution $(0.27 \%$ $\mathrm{NaCl}$ ) and HC-067047 (300 nmol), or their vehicle (4\% DMSO and 4\% tween 80 in $0.9 \% \mathrm{NaCl}$ ), and acute nociceptive responses were recorded over the next $10 \mathrm{~min}[40,41]$. Some C57BL/6 J mice were treated intraperitoneally (i.p.) with ibuprofen-acyl glucuronide (1, 10 and $100 \mathrm{mg} / \mathrm{kg}$ ), HC-030031 (1, 10 and $100 \mathrm{mg} / \mathrm{kg}$ ), ibuprofen (1, 10 and $100 \mathrm{mg} / \mathrm{kg}$ ) or their vehicle ( $4 \%$ DMSO and $4 \%$ tween 80 in $0.9 \% \mathrm{NaCl}$ ) and $30 \mathrm{~min}$ after treatment the acute nociceptive response to i.pl. injection of AITC $(10 \mathrm{nmol})$ was recorded over the next $10 \mathrm{~min}$ [40]. Other C57BL/6 J mice were treated intraperitoneally (i.p.) with ibuprofen-acyl glucuronide (10 and $100 \mathrm{mg} / \mathrm{kg}$ ), ibuprofen (10 and $100 \mathrm{mg} / \mathrm{kg})$, HC-030031 (100 mg/kg) [40], capsazepine (4 mg/kg) [40], HC-067047 (10 mg/kg) [42], or their vehicle (4\% DMSO and 4\% tween 80 in $0.9 \% \mathrm{NaCl}$ ) and $30 \mathrm{~min}$ after treatment the acute nociceptive responses to i.pl. injection of acrolein and $\mathrm{ZnCl}_{2}$ (all, $10 \mathrm{nmol}$ ), capsaicin $(1 \mathrm{nmol})$ or hypotonic solution $(0.27 \% \mathrm{NaCl})$ were recorded over the next $10 \mathrm{~min}$ [40].

For the carrageenan model, C57BL/ $6 \mathrm{~J}$ mice were injected (i.pl., $20 \mu \mathrm{l} / \mathrm{paw})$ with carrageenan $(300 \mu \mathrm{g})$, or its vehicle $(0.9 \% \mathrm{NaCl})$, and mechanical allodynia was recorded $180 \mathrm{~min}$ after injection [17]. Some C57BL/6 J mice were treated (150 min after carrageenan) by i.pl. ( $20 \mu \mathrm{l} /$ paw) injection with ibuprofen-acyl glucuronide, ibuprofen (all, $100 \mathrm{nmol}$ ), or a mixture of ibuprofen-acyl glucuronide or ibuprofen and HC-030031 (all, $100 \mathrm{nmol}$ ), or their vehicle (all 4\% DMSO and 4\% tween 80 in $0.9 \% \mathrm{NaCl}$ ). Additional $\mathrm{C} 57 \mathrm{BL} / 6 \mathrm{~J}$ mice were treated (150 min after carrageenan) with i.p. ibuprofen-acyl glucuronide, ibuprofen (both 10 and $100 \mathrm{mg} / \mathrm{kg}$ ), HC-030031 (100 mg/kg), indomethacin $(30 \mathrm{mg} / \mathrm{kg})$ or their vehicles (4\% DMSO and $4 \%$ tween 80 in $0.9 \% \mathrm{NaCl}$ ) [40]. Some Trpa1 ${ }^{-/-}$mice were treated (150 min after carrageenan) with i.p. ibuprofen-acyl glucuronide $(100 \mathrm{mg} / \mathrm{kg})$.

For the formalin test, C57BL/6J mice were injected (i.pl., $20 \mu \mathrm{l} /$ paw) with formalin $(0.5 \%$ in $0.9 \% \mathrm{NaCl})$ and the acute nociceptive response was monitored over the next $60 \mathrm{~min}$ and reported as phase I (0-10 $\mathrm{min})$ and phase II (11-60 min) [16]. Some animals were pretreated by i.pl. $(20 \mu \mathrm{l} / \mathrm{paw})$ injection ( $10 \mathrm{~min}$ before) with ibuprofenacyl glucuronide and ibuprofen (both $100 \mathrm{nmol}$ ) or their vehicle (all $4 \%$ DMSO and $4 \%$ tween 80 in $0.9 \% \mathrm{NaCl}$ ) or with i.p. ibuprofen-acyl glucuronide, ibuprofen (both 10 and $100 \mathrm{mg} / \mathrm{kg}, 30 \mathrm{~min}$ before), HC030031 (100 mg/kg, $60 \mathrm{~min}$ before) [16] and indomethacin (30 mg/kg,
$30 \mathrm{~min}$ before) [40].

\subsubsection{Acute nociceptive test and Von Frey hair test}

Immediately after the i.pl. (20 $\mu \mathrm{l} / \mathrm{paw})$ injection with tested compounds, mice were placed inside a plexiglass chamber and the total time spent in lifting/licking the injected hind paw, as an indicative time of acute nociceptive response, was recorded for $10 \mathrm{~min}$. The i.pl. injection with vehicles of tested compounds produced nociceptive behavior for a maximum of $2 \mathrm{~s}$. Mechanical allodynia was measured in mice by the up-and-down paradigm [43]. Briefly, mice were placed individually in a plexiglass chamber designed for the evaluation of mechanical thresholds [43] and were habituated to the room temperature for at least $1 \mathrm{~h}$ before the test. Then, a series of 7 Von Frey hairs in logarithmic increments of force $(0.07,0.16,0.4,0.6,1,1.4,2 \mathrm{~g})$ was used to stimulate the injected hind paw. The response was considered positive when the mouse strongly withdrew the paw. The stimulation started with the $0.6 \mathrm{~g}$ filament. The von Frey hairs were applied with sufficient force to cause slight buckling and held for approximately $2-4 \mathrm{~s}$. Absence of response after $5 \mathrm{~s}$ led to the use of a filament with increased weight, whereas a positive response led to the use of a weaker (i.e. lighter) filament. Six measurements were collected for each mouse or until four consecutive positive or negative responses occurred. The $50 \%$ mechanical withdrawal threshold (expressed in $\mathrm{g}$ ) response was then calculated from these scores, as previously described $[43,44]$. Mechanical nociceptive threshold was determined before (basal level) and after different treatments.

\subsection{Prostaglandin $E_{2}$ assay}

C57BL/6 J or Trpa1 ${ }^{-/-}$mice were injected (i.pl. $20 \mu 1 /$ paw) with carrageenan $(300 \mu \mathrm{g})$ or its vehicle $(0.9 \% \mathrm{NaCl})$ and $180 \mathrm{~min}$ after treatment the injected paws were collected, weighed, frozen in liquid nitrogen and homogenized in sodium phosphate buffer (PBS $0.1 \mathrm{M}, \mathrm{pH}$ 7.4) containing indomethacin $(20 \mu \mathrm{M})$ to avoid further activation of COX. Homogenates were centrifuged at $9000 \times g$ for $20 \mathrm{~min}$ at $4{ }^{\circ} \mathrm{C}$ [45]. Supernatants were collected and $\mathrm{PGE}_{2}$ levels were measured by enzyme immunoassay (Abcam, Cambridge, UK), according to the manufacturer's instructions. Some C57BL/6 J were treated (150 min after carrageenan) by i.pl. ( $20 \mu \mathrm{l} / \mathrm{paw})$ injection with ibuprofen-acyl glucuronide, ibuprofen (both, $100 \mathrm{nmol}$ ) or their vehicles (4\% DMSO and $4 \%$ tween 80 in $0.9 \% \mathrm{NaCl}$ ). Other animals were treated (150 min after carrageenan) by i.p. injection with ibuprofen-acyl glucuronide, ibuprofen (both, $100 \mathrm{mg} / \mathrm{kg}$ ), HC-030031 (100 mg/kg, i.p.), indomethacin (30 mg/kg, i.p.), or their vehicles (4\% DMSO and $4 \%$ tween 80 in $0.9 \%$ $\mathrm{NaCl})$.

\subsection{Molecular modeling}

\subsubsection{Protein structure refinement}

Molecular modeling studies were performed using the structure of the human TRPA1 ion channel determined by electron cryo-microscopy (PDB code 3J9P) [46]. The missing side chains of partially resolved residues as well as the missing loop sequences within the protein core structure were automatically reconstructed by using Modeller software [47]. The refined structure was then energy minimized in explicit water environment, after being embedded in a lipid bilayer. The creation of the phospholipid bilayer constituted by POPC (1-palmitoyl-2-oleoyl-snglycero-3-phosphocholine) molecules and the insertion of the protein inside it were performed using Visual Molecular Dynamics (VMD) software [48]. The energy minimization was then carried out with AMBER software, version 16 . The system was solvated with a $15 \AA$ water cap on both the "intracellular" and the "extracellular" sides using the TIP3P solvent model, while chloride ions were added as counterions to neutralize the system. The Lipid14 parameters [49] were assigned to POPC molecules. Three sequential minimization stages, each consisting of 8000 steps of steepest descent followed by conjugate gradient, were 
A Ibuprofen (Ibu)<smiles>CC(C)Cc1ccc(C(C)C(=O)O)cc1</smiles>

Ibuprofen Acyl- $\beta$-D-glucuronide (IAG)<smiles>[CH]C(C)Cc1ccc(C(C)C(=O)OC2OC(C(=O)O)C(O)C(O)C2O)cc1</smiles>

\section{C hTRPA1-HEK293}

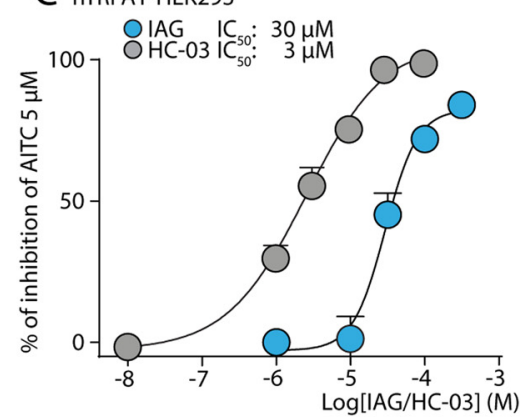

B hTRPA1-HEK293
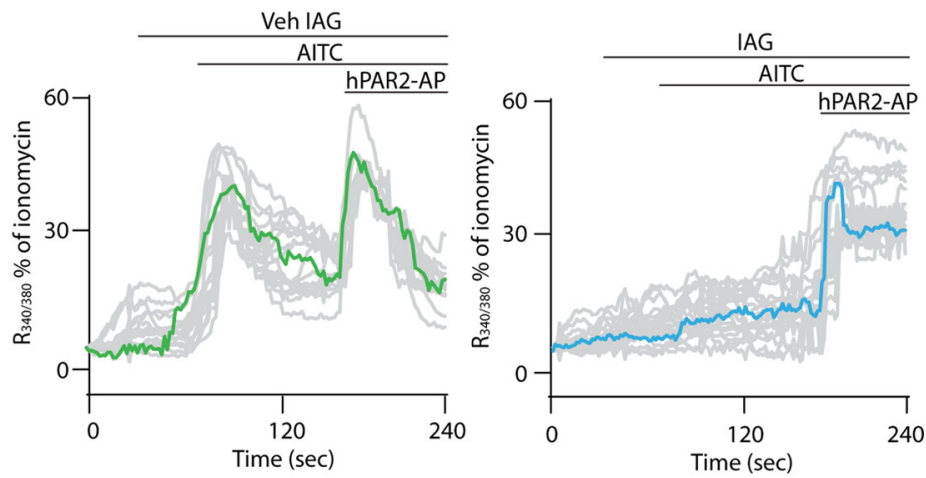

D hTRPA1-HEK293

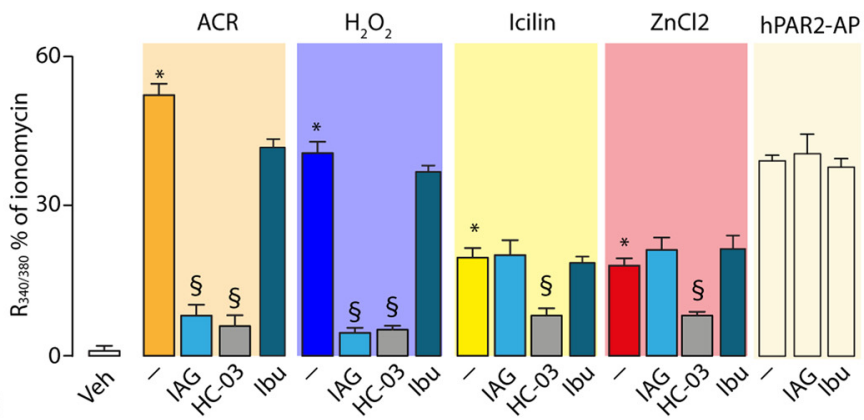

$\mathrm{F}_{\text {hTRPV1-HEK293 }} \mathrm{G}_{\text {hTRPA1/N1-HEK293 }}$

E 3C/K-Q hTRPA1-HEK293

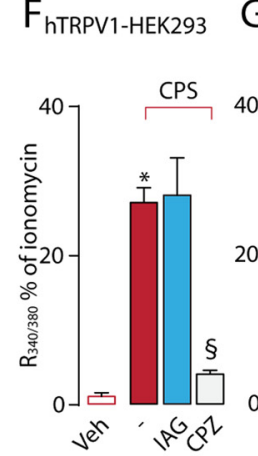

]$_{0}$ AITC
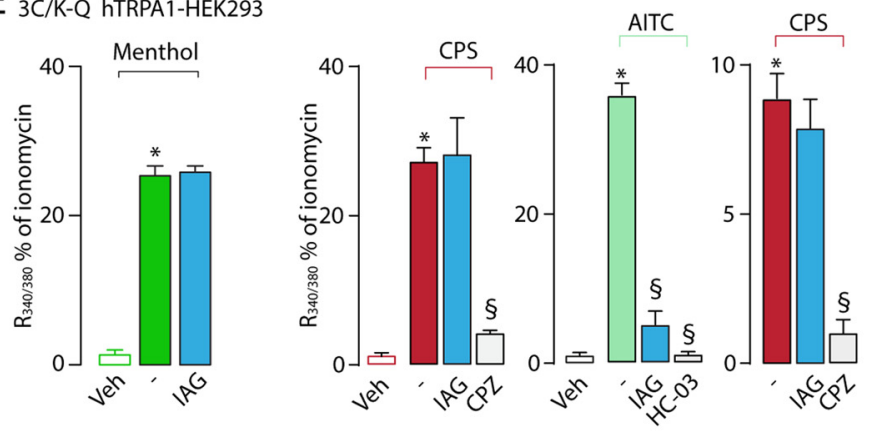

$\mathrm{H}_{\text {hTRPV4-HEK293 }}$

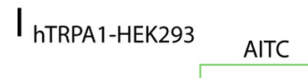

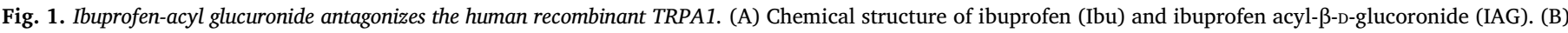

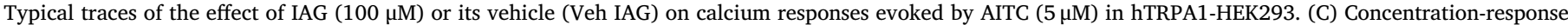

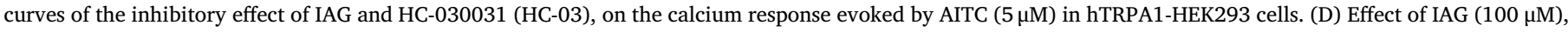

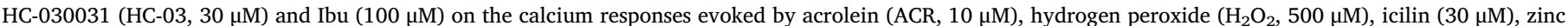

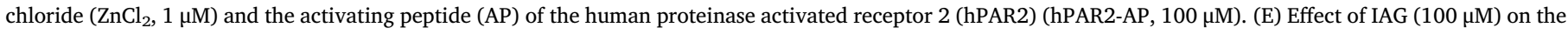

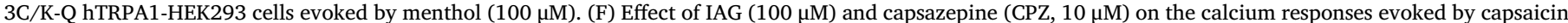

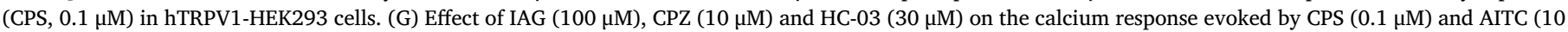

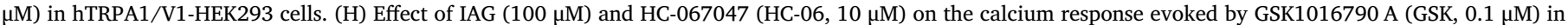

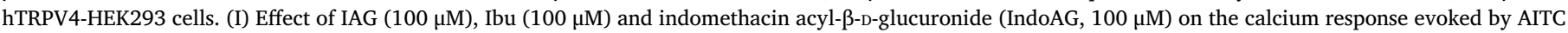

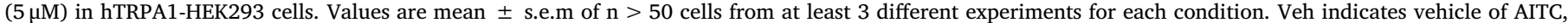

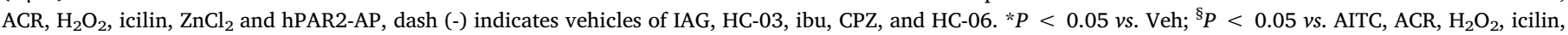
$\mathrm{ZnCl}_{2}$, CPS or GSK. One-way ANOVA and post-hoc Bonferroni's test.

thus performed. In the first stage, a position restraint of $100 \mathrm{kcal} /$ $\mathrm{mol} \cdot \AA^{2}$ was applied on the whole protein and phospholipid bilayer in order to uniquely minimize the positions of the water molecules. In the second stage, the same position restraint was only applied on the protein residues, thus leaving the phospholipid molecules free, while in the last stage only the protein $\alpha$ carbons were restrained with a harmonic potential of $30 \mathrm{kcal} / \mathrm{mol} \cdot \AA^{2}$.

\subsubsection{Ibuprofen-acyl glucuronide -TRPA1 covalent binding analysis}

Molecular docking studies were performed on the structurally refined and energy minimized structure of hTRPA1 using the covalent docking protocol implemented in Gold software [50]. The calculations were performed selecting C621, C641 and C665 as the covalently modified residues and the acyl portion of ibuprofen-acyl glucuronide belonging to $(S)$-ibuprofen as the ligand moiety covalently bound to the residues. For each of the three S-acyl-cysteine thioester adducts, 100 different ligand binding orientations were evaluated, and the top-scored disposition was considered for further analyses. The three ligand-protein complexes obtained were then subjected to molecular dynamic (MD) simulations with AMBER 16. Each complex was initially subjected to three stages of energy minimization as performed for protein refinement. Subsequently, the temperature of the system was gradually raised from 0 to $300 \mathrm{~K}$ through a brief constant-volume MD simulation where a position restraint of $30 \mathrm{kcal} / \mathrm{mol} \cdot \AA^{2}$ was applied on the protein 
$\alpha$ carbons. The system was then relaxed through a 500 ps constantpressure MD simulation in which the harmonic potential applied on the protein $\alpha$ carbons was gradually removed and a Langevin thermostat was used to keep the temperature at $300 \mathrm{~K}$. Finally, $20 \mathrm{~ns}$ of constantpressure MD simulation production were performed by leaving the whole system free and using the Monte Carlo barostat with anisotropic pressure scaling for pressure control. All simulations were performed using particle mesh Ewald electrostatics with a cutoff of $10 \AA$ for nonbonded interactions and periodic boundary conditions. A simulation step of $2.0 \mathrm{fs}$ was employed, as all bonds involving hydrogen atoms were kept rigid using SHAKE algorithm. The Lipid14 parameters were assigned to POPC molecules, while GAFF parameters were used for the ligand, whose partial charges were calculated with the AM1-BCC method as implemented in the Antechamber suite of AMBER 16. Linear interaction energy (LIE) evaluations were performed between the ligand (i.e. the atoms constituting the S-acyl moiety belonging to ibuprofen of the covalent adduct) and the protein residues located within a 12 A radius from it. The ccptraj analysis program module of AMBER 16, was employed for the calculations, using the trajectories extracted from the last $10 \mathrm{~ns}$ of MD simulation, for a total of 100 snapshots (with a time interval of $100 \mathrm{ps}$ ).

\subsection{IL-8 release assay}

For IL-8 ELISA assay, NHBE cells were seeded in complete culture medium in 48 -well plates, grown to $~ 80-90 \%$ confluence, and incubated overnight in serum-free medium before treatments. All the treatments were then performed in serum free medium. Cells were pretreated (30 min) with HC-030031 (50 $\mu \mathrm{M})$, ibuprofen-acyl glucuronide and ibuprofen (both, $100 \mu \mathrm{M})$ or vehicle (1\% DMSO) before incubation $\left(18 \mathrm{~h}\right.$ at $37^{\circ} \mathrm{C}$ in $\left.5 \% \mathrm{CO}_{2}\right)$ with freshly prepared AITC $(10-30 \mu \mathrm{M})$ and TNF- $\alpha(0.2 \mathrm{nM})$. Supernatants were then collected, and the human IL-8 content was assayed using a paired antibody quantitative ELISA kit (Invitrogen, Milan, Italy) (detection limit: $5 \mathrm{pg} / \mathrm{ml}$ ). The assay was performed according to the manufacturer's instructions.

\subsection{Data and statistical analysis}

All data were expressed as mean \pm s.e.m or confidence interval (CI). Statistical analysis was performed by the one-way analysis of variance (ANOVA) followed by the post-hoc Bonferroni's test for comparisons of multiple groups. For behavioural experiments with repeated measures, the two-way ANOVA followed by the post-hoc Bonferroni's test was used. Statistical analysis was performed on raw data using GraphPad software (GraphPad Prism version 6.00, San Diego, CA, USA). $\mathrm{P}<0.05$ was considered statistically significant.

\section{Results}

\subsection{Ibuprofen-acyl glucuronide antagonizes human and rodent TRPA1}

The ability of ibuprofen-acyl glucuronide to affect TRPA1-mediated calcium responses was studied by using a single cell assay in human and rodent cells expressing TRPA1. Ibuprofen-acyl glucuronide did not evoke per se any calcium response in hTRPA1-HEK293 cells (Fig. 1B,I). However, ibuprofen-acyl glucuronide, like the selective TRPA1 antagonist, HC-030031, inhibited in a concentration-dependent manner calcium response evoked by AITC [IC ${ }_{50}, 30$ (CI, 22-40) $\mu \mathrm{M}$ and 3 (CI, 1.4-6) $\mu \mathrm{M}$, respectively] (Fig. 1C). Ibuprofen-acyl glucuronide reduced calcium responses evoked by additional reactive TRPA1 agonists, such as acrolein or hydrogen peroxide $\left(\mathrm{H}_{2} \mathrm{O}_{2}\right)$ (Fig. 1D), but did not affect the responses by non-reactive agonists, icilin and zinc chloride $\left(\mathrm{ZnCl}_{2}\right)$ (Fig. 1D), which do not act by binding key cysteine residues of TRPA1 [51,52]. HC-030031 abolished the calcium responses evoked by both reactive and non-reactive agonists (Fig. 1D). Ibuprofen-acyl glucuronide did not attenuate the rapid calcium responses evoked by acute exposure to the activating peptide (AP) of the human protease-activated receptor 2 (hPAR2) (hPAR2-AP) (Fig. 1D). This finding supports the selectivity of ibuprofen-acyl glucuronide. The ability of ibuprofen-acyl glucuronide to inhibit TRPA1 by binding key cysteine and lysine residues was further proved by the study of the mutated human TRPA1 (3C/K-Q hTRPA1), which lacks the cysteine and lysine residues, required for channel activation by reactive agonists, and which responds to menthol $[9,11,12]$. Calcium responses to menthol $(100 \mu \mathrm{M})$ were unaffected by ibuprofen-acyl glucuronide in 3C/K-Q hTRPA1-HEK293 cells (Fig. 1E).

Selectivity of ibuprofen-acyl glucuronide for TRPA1 was robustly confirmed by a series of observations. In hTRPV1-HEK293, calcium responses to the TRPV1 agonist, capsaicin, were ablated by the TRPV1 selective antagonist, capsazepine, but were unaffected by ibuprofenacyl glucuronide (Fig. 1F). In hTRPA1/TRPV1-HEK293 co-expressing cells, responses to capsaicin were attenuated by capsazepine, but not by ibuprofen-acyl glucuronide, whereas responses to AITC were ablated by ibuprofen-acyl glucuronide and HC-03003, but not by capsazepine (Fig. 1G). Moreover, in hTRPV4-HEK293 cells, calcium responses to the selective TRPV4 agonist, GSK1016790 A, were ablated by a TRPV4 antagonist, HC-067047, but were unaffected by ibuprofen-acyl glucuronide (Fig. 1H). Ibuprofen did not evoke per se any calcium responses and did not affect the calcium responses evoked by AITC, acrolein or $\mathrm{H}_{2} \mathrm{O}_{2}$ in hTRPA1-HEK293 cells (Fig. 1D,I). The glucuronidated metabolite of indomethacin, acyl- $\beta$-D-glucuronide, neither evoked calcium response nor reduced the calcium response evoked by AITC in hTRPA1HEK293 cells (Fig. 1I).

Ibuprofen-acyl glucuronide also inhibited the AITC-evoked calcium response in IMR90 cells, a cell line where TRPA1 was originally cloned [53], (Fig. 2A), and which constitutively expresses the channel. Ibuprofen-acyl glucuronide [IC $\mathrm{I}_{50}, 60(\mathrm{CI}, 45-88) \mu \mathrm{M}$ ] and HC-030031 $\left[\mathrm{IC}_{50 s}, 3(\mathrm{CI}, 2-6) \mu \mathrm{M}\right]$ reduced AITC-evoked calcium responses (Fig. 2B,C). Ibuprofen-acyl glucuronide failed to attenuate rapid calcium responses evoked by acute exposure to hPAR2-AP (Fig. 2C). Ibuprofen-acyl glucuronide [IC ${ }_{50}, 50$ (CI, 40-70) $\mu \mathrm{M}$ ] and HC-030031 $\left[\mathrm{IC}_{50}, 1\right.$ (CI, 0.3-1.8) $\mu \mathrm{M}$ ] reduced AITC-evoked calcium responses in cultured rat dorsal root ganglion (rDRG) neurons, which express the native TRPA1 (Fig. 2D-F). Ibuprofen-acyl glucuronide did not affect calcium responses to other excitatory stimuli, such as capsaicin and high potassium chloride (KCl) (Fig. 2G). Thus, ibuprofen-acyl glucuronide was able to selectively block the human and rodent TRPA1 channel.

\subsection{Mode of TRPA1 targeting by ibuprofen-acyl glucuronide}

A covalent docking approach was applied to evaluate the binding mode of the possible covalent adducts formed by transacylation of ibuprofen-acyl glucuronide with residues C621, C641 and C665, since the mutation of these residues abolished the inhibitory activity of the ligand on TRPA1. Moreover, these solvent accessible residues are located in an allosteric nexus of the TRPA1 channel, suitable for the detection of electrophile agonists [46], and have been demonstrated to exert a fundamental role in TRPA1 activation by reactive agonists like AITC [11]. The structure of the human TRPA1 ion channel recently determined by electron cryo-microscopy (PDB code 3J9P) was employed for this analysis [46]. After refining the protein structure (see Materials and Methods for details), the covalent docking protocol implemented in Gold software was applied to evaluate the binding orientations of the thioester adducts formed by reaction of ibuprofen-acyl glucuronide with C621, C641 and C665, corresponding to the acylation of cysteine thiol groups with the ligand acyl moiety belonging to ibuprofen. For each S-acyl-cysteine adduct, the top-scored binding disposition of the ligand was taken into account and further analyzed through MD simulation studies. After embedding the covalently modified protein in a lipid bilayer and solvating the system with explicit water molecules, $20 \mathrm{~ns}$ of MD simulation were performed (see Materials 
A IMR90
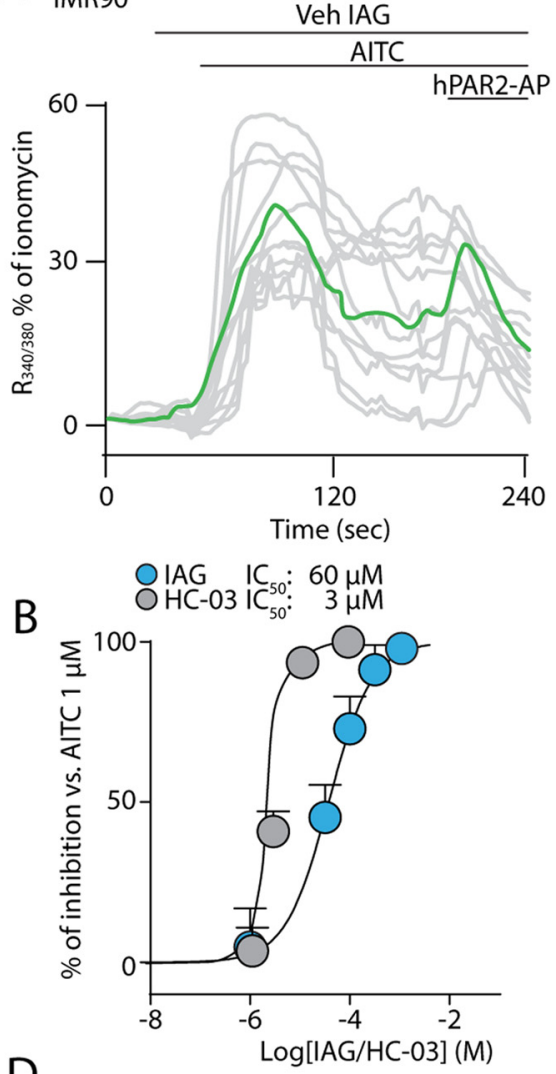

$D_{\text {Rat DRG neurons }}$

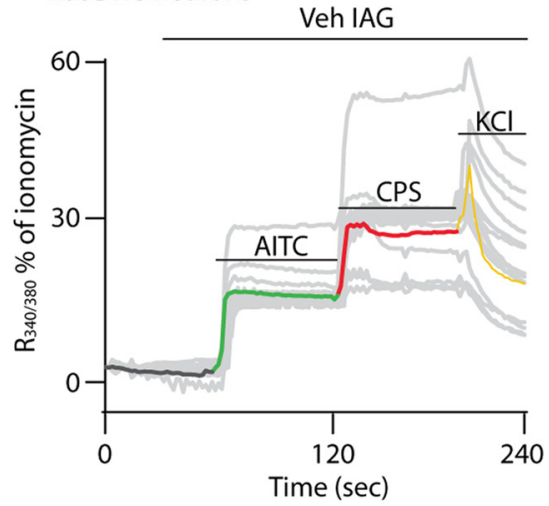

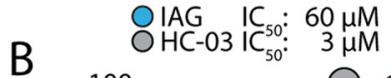
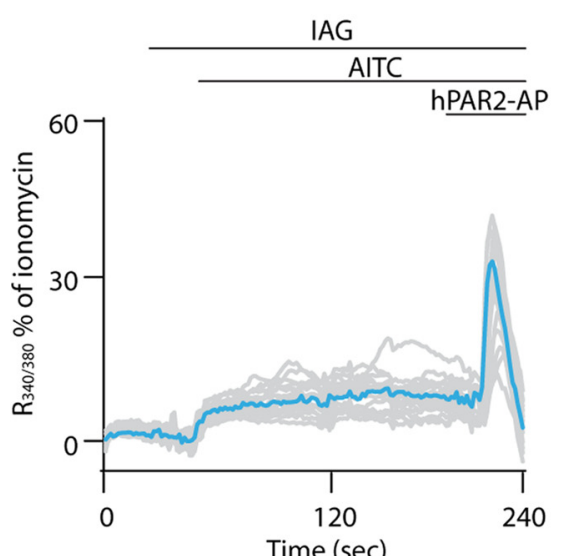

C

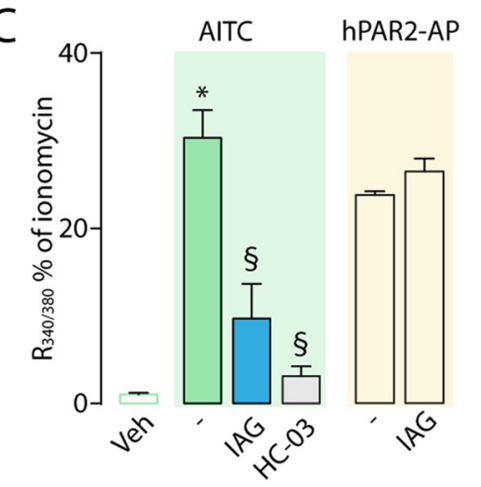

Fig. 2. Ibuprofen-acyl glucuronide antagonizes the human and rat native TRPA1. (A) Typical traces of the effect of pre-exposure $(10 \mathrm{~min})$ to Veh (vehicle) IAG/IAG $(100 \mu \mathrm{M})$ on the calcium response evoked by AITC $(1 \mu \mathrm{M})$ and the hPAR2-AP $(100 \mu \mathrm{M})$ in IMR90 cells. (B) Concentration-response curves of the inhibitory effect of IAG and HC-030031 (HC-03), on the calcium response evoked by AITC $(1 \mu \mathrm{M})$ in IMR90 cells. (C) Pooled data of the effect of IAG and HC-03 on the calcium response evoked by AITC $(1 \mu \mathrm{M})$ in IMR90 cells. (D) Typical traces of the inhibitory effect of pre-exposure $(10 \mathrm{~min})$ to Veh IAG/IAG $(100 \mu \mathrm{M})$ on the calcium response evoked by AITC $(10 \mu \mathrm{M})$, capsaicin (CPS, $0.1 \mu \mathrm{M})$ and $\mathrm{KCl}$ $(50 \mathrm{mM})$ in rDRG neurons. (E) Concentrationresponse curves of the inhibitory effect of IAG and HC-03 on the calcium response evoked by AITC in rDRG neurons. (F) Pooled data of the effect of IAG and HC-03 on the calcium response evoked by AITC $(10 \mu \mathrm{M})$ in rDRG neurons. (G) Pooled data of the effect of IAG $(100 \mu \mathrm{M})$ on the responses evoked by capsaicin (CPS, $0.1 \mu \mathrm{M})$ or high potassium chloride $(\mathrm{KCl}$, $50 \mathrm{mM}$ ) in rDRG neurons. Values are mean \pm s.e.m of $n>25$ cells from at least 3 different experiments for each condition. Veh indicates vehicle of AITC, dash (-) indicates vehicles of IAG and HC-03. ${ }^{*} P<0.05 v s$. Veh; ${ }^{\S} P<0.05$ vs. AITC. One-way ANOVA and post-hoc Bonferroni's test.
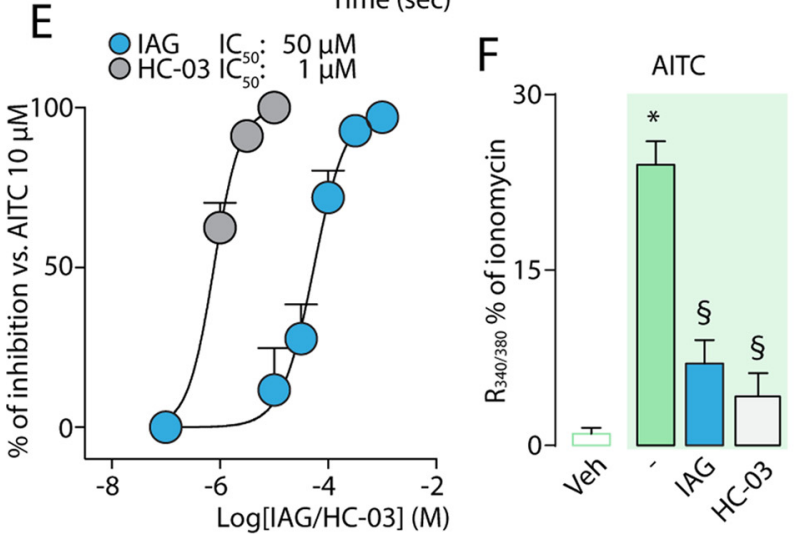
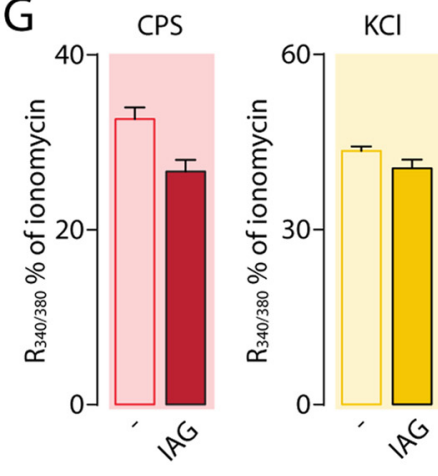

and Methods for details). The results were then analyzed in terms of ligand-protein interaction energy, in order to evaluate the reliability of the predicted covalent adducts from an energetic point of view. For this purpose, the linear interaction energy (LIE) approach was employed.
LIE evaluations allow the calculation of the non-bonded interactions between the ligand and the surrounding protein residues from the trajectories generated through MD simulations. Electrostatic and van der Waals energetic contributions are calculated for each MD snapshot 


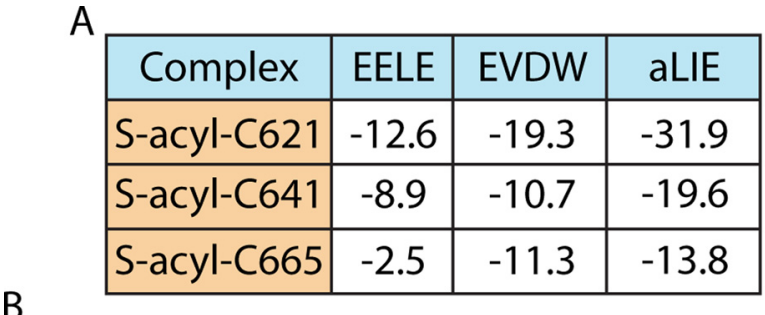

B

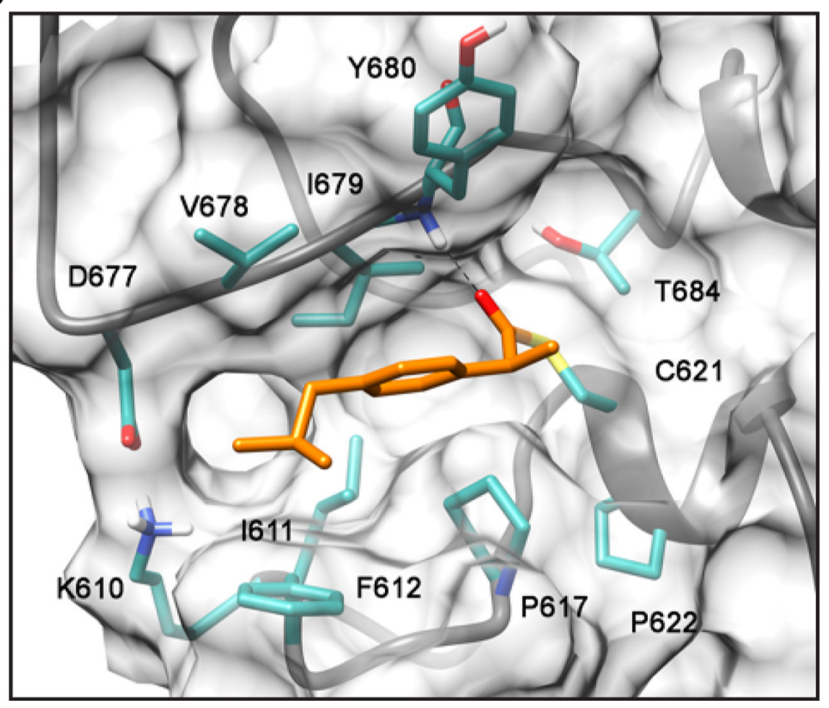

Fig. 3. Ibuprofen-acyl glucuronide interact with hTRPA1 in molecular dynamic model, (A) Linear Interaction Energy (LIE) results for the three covalent complexes of hTRPA1 obtained by transacylation of C621, C641 and C665 by IAG. Data are expressed as $\mathrm{kcal} / \mathrm{mol}$. (B) Minimized average structure of the S-acylC621 hTRPA1 ion channel. The covalent ligand is shown in orange, while the protein residues are colored dark cyan.

and the obtained values are then used to derive the average total ligand-protein interaction energy. In this case, LIE evaluations were performed between the atoms constituting the acyl moiety belonging to ibuprofen of the three predicted S-acyl-cysteine covalent adducts and the protein residues located within a radius of $12 \AA$. The MD trajectories extracted from the last $10 \mathrm{~ns}$ of MD simulation were used for the calculations, for a total of 100 snapshots (with a time interval of $100 \mathrm{ps}$ ). The average LIE values (aLIE) were obtained for the three different covalent complexes as the sum of the average electrostatic (EELE) and van der Waals (EVDW) energy contributions expressed as $\mathrm{kcal} / \mathrm{mol}$ (Fig. 3A).

The linear interaction energy evaluations highlighted the S-acylC621 thioester as the most energetically favored covalent adduct, presenting a linear interaction energy value $(-31.9 \mathrm{kcal} / \mathrm{mol})$ exceeding those estimated for the S-acyl-C641 and S-acyl-C665 covalent complexes by about 12 and $18 \mathrm{kcal} / \mathrm{mol}$, respectively. Interestingly, the homolog of C621 in mouse TRPA1 (C622) was found to be the cysteine residue that most affected TRPA1 activation by reactive agonists, since its mutation completely abolished the responsiveness of TRPA1 to AITC [12]. The average binding disposition of ibuprofen within the S-acylC621 thioester adduct obtained from the last $10 \mathrm{~ns}$ of molecular dynamics simulation was obtained (Fig. 3B). The acyl chain belonging to ibuprofen perfectly fits a small hydrophobic pocket constituted by I611, F612, P617, V678, I679 and Y680, delimited by K610 and D677 from one side and T684 from the other. In particular, the aromatic moiety of the ligand lies on the P617 side chain, forming lipophilic interactions with this residue, as well as with 1622 and I679, while the $p$-isobutyl group is sandwiched between F612 and V678, showing strong hydrophobic contacts with this latter residue. Moreover, the ligand carbonyl oxygen forms a hydrogen bond with the backbone nitrogen of Y680 that is maintained for about $80 \%$ of the entire molecular dynamics simulation, thus contributing to the anchoring of the ligand to the hydrophobic pocket. Interestingly, the S-acyl-C621 thioester was the only covalent complex in which a stable hydrogen bond between the ligand portion and the surrounding protein residues was observed (Fig. 3B).

\subsection{Ibuprofen-acyl glucuronide selectively inhibits TRPA1-mediated nocifensor responses}

Next, we speculated that ibuprofen-acyl glucuronide produces in vivo antinociceptive effects via TRPA1 antagonism. The intraplantar $(20 \mu \mathrm{l} / \mathrm{paw})$ administration of ibuprofen-acyl glucuronide or HC030031 dose-dependently reduced ID $_{50}$ of $4(\mathrm{CI}, 2-9) \mathrm{nmol}$, and $\mathrm{ID}_{50}, 8$ (CI, 3-23) nmol, respectively] the acute nociceptive response evoked by the injection of AITC (intraplantar). Maximum inhibition on the nociceptive responses evoked by AITC (intraplantar) was $72 \% \pm 2 \%$ for ibuprofen-acyl glucuronide and, $89 \% \pm 1.7 \%$ for HC-030031 ( $=6$, $\mathrm{p}<0.05$ ) (Fig. 4A). Acute nociceptive responses induced by intraplantar capsaicin and hypotonic solution (TRPV1 and TRPV4 -mediated responses, respectively) were attenuated by injection of the respective channel antagonists, capsazepine and HC-067047, but were unaffected by ibuprofen-acyl glucuronide (all intraplantar) (Fig. 4B). The nociceptive response evoked by acrolein (intraplantar) was inhibited by ibuprofen-acyl glucuronide and HC-030031 (both intraplantar) (Fig. 4C). In contrast, ibuprofen-acyl glucuronide (intraplantar) failed to affect nociceptive response evoked by the noncovalent agonist, $\mathrm{ZnCl}_{2}$ (intraplantar), which, however, was attenuated by HC-030031 (intraplantar) (Fig. 4C). Ibuprofen intraplantar administration failed to affect the acute nociceptive response evoked by either AITC, acrolein or $\mathrm{ZnCl}_{2}$ (all intraplantar) (Fig. 4C,D).

The systemic (intraperitoneal) administration of HC-030031, ibuprofen-acyl glucuronide and ibuprofen dose-dependently [ID ${ }_{50 s} 7$ (CI, 4-14) $\mathrm{mg} / \mathrm{kg}, 10$ (CI, 4-20) $\mathrm{mg} / \mathrm{kg}$ and $\mathrm{ID}_{50 \mathrm{~s}} 27$ (CI, 8-90) mg/kg, respectively] reduced the nociceptive responses to AITC (intraplantar) (Fig. 4E). Maximum inhibition by ibuprofen $(42 \% \pm 3 \%)$ was lower than those produced by ibuprofen-acyl glucuronide $(76 \% \pm 4 \%)$ and HC-030031 (83 $\pm 4 \%$ ) (all $100 \mathrm{mg} / \mathrm{kg}, \mathrm{n}=6$ each, $P<0.05$ ibuprofen $v$ s. both ibuprofen-acyl glucuronide and HC-030031) (Fig. 4E). Systemic (intraperitoneal) ibuprofen-acyl glucuronide did not affect the nociceptive responses evoked by either capsaicin or a hypotonic solution, which, however, were attenuated by the TRPV1 and TRPV4 antagonists, capsazepine and HC067047, respectively (Fig. 4F). Systemic (intraperitoneal) ibuprofen-acyl glucuronide (both, 10 and $100 \mathrm{mg} / \mathrm{kg}$ ) reduced the nociception evoked by acrolein but not that evoked by $\mathrm{ZnCl}_{2}$ (Fig. 4G,H), whereas only $100 \mathrm{mg} / \mathrm{kg}$, but not $10 \mathrm{mg} / \mathrm{kg}$ (both intraperitoneal) ibuprofen reduced the nociceptive responses evoked by acrolein (Fig. 4G). Ibuprofen-acyl glucuronide at both 10 and $100 \mathrm{mg} /$ $\mathrm{kg}$ was more effective than the respective doses of ibuprofen (Fig. 4E,G). Finally, systemic (intraperitoneal) HC-030031 inhibited the nociceptive responses evoked by both acrolein and $\mathrm{ZnCl}_{2}$ (Fig. 3G,H).

\subsection{Ibuprofen-acyl glucuronide reduces TRPA1-dependent hyperalgesia and nociception in models of inflammatory pain}

We tested the ability of ibuprofen-acyl glucuronide to reduce mechanical allodynia evoked by intraplantar carrageenan injection in the mouse hind paw. Carrageenan induces a prolonged mechanical allodynia that is in part mediated by TRPA1 $[17,18]$. Ibuprofen-acyl glucuronide (intraplantar, $2.5 \mathrm{~h}$ after carrageenan) almost completely attenuated mechanical allodynia (Fig. 5A), whereas an identical dose of ibuprofen produced a partial inhibition (Fig. 5B). A combination of HC030031 and ibuprofen (both intraplantar) increased the effect of ibuprofen alone, but did not further affect the inhibitory response to ibuprofen-acyl glucuronide alone (Fig. 5A,B).

A low systemic (intraperitoneal) dose $(10 \mathrm{mg} / \mathrm{kg}$ ) of ibuprofen-acyl glucuronide, but not ibuprofen, significantly reduced carrageenan- 

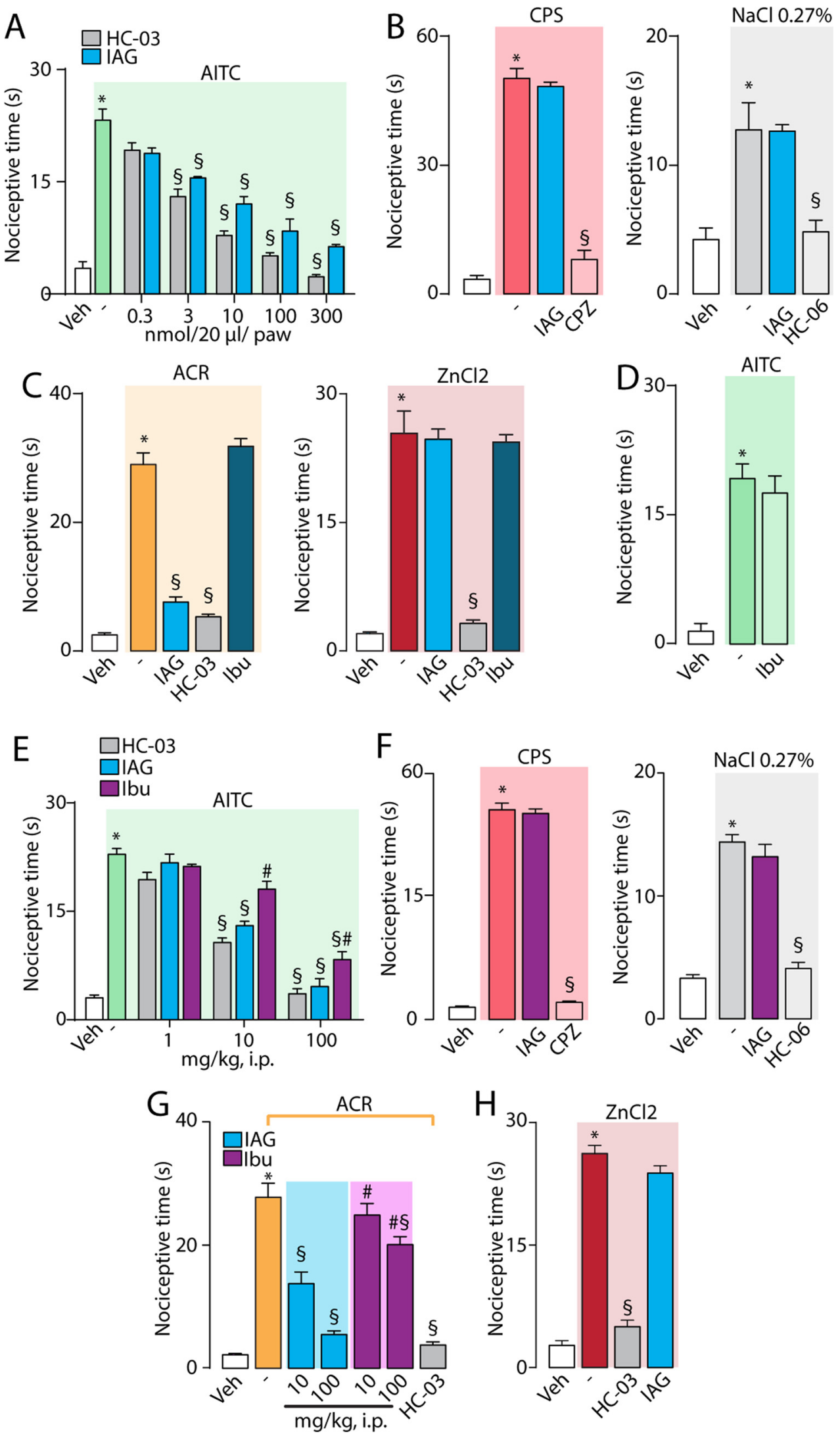

Fig. 4. Ibuprofen-acyl glucuronide inhibits nociceptive responses evoked by reactive TRPA1 agonists in mice. (A) Dose-dependent inhibitory effect of intraplantar (i.pl., $20 \mu \mathrm{l} /$ paw) administration of IAG $(0.3-300 \mathrm{nmol})$ and HC-030031 (HC-03, 0.3-300 nmol) on the acute nociceptive response evoked by i.pl. allyl isothiocyanate (AITC, $20 \mathrm{nmol}$ ) in C57BL/6 J mice. (B) Effect of IAG (300 nmol), capsazepine (CPZ, $300 \mathrm{nmol}$ ) and HC-067047 (HC-06, $300 \mathrm{nmol}$ ) on the acute nociceptive response evoked by i.pl. CPS (1 nmol) and $\mathrm{NaCl} 0.27 \%$ in C57BL/6 J mice. (C) Effect of i.pl. IAG (300 nmol), HC-03 $(300 \mathrm{nmol})$ and ibuprofen (Ibu, $300 \mathrm{nmol}$ ) on the nociceptive response evoked by i.pl. acrolein (ACR, $10 \mathrm{nmol})$ and zinc chloride $\left(\mathrm{ZnCl}_{2}, 10 \mathrm{nmol}\right)$ in $\mathrm{C} 57 \mathrm{BL} / 6 \mathrm{~J}$ mice. (D) Effect of Ibu $(300 \mathrm{nmol})$ on the nociceptive response evoked by i.pl. AITC $(20 \mathrm{nmol})$ in C57BL/6 J mice. (E) Dose-response inhibitory effect of intraperitoneal (i.p.) administration of IAG, Ibu and HC-03 (all, $1-100 \mathrm{mg} / \mathrm{kg}$ ) on the acute nociceptive response evoked by i.pl. AITC (20 nmol) in C57BL/6 J mice. (F) Effect of i.p. IAG $(100 \mathrm{mg} / \mathrm{kg}) \mathrm{CPZ}(4 \mathrm{mg} / \mathrm{kg})$ and HC-06 $(10 \mathrm{mg} / \mathrm{kg})$ on the acute nociceptive response evoked by i.pl. CPS ( $1 \mathrm{nmol})$ and $\mathrm{NaCl} 0.27 \%$ in C57BL/6 J mice. (G) Effect of i.p. IAG, Ibu (both, 10 and $100 \mathrm{mg} / \mathrm{kg}$ ) and HC-03 $(100 \mathrm{mg} / \mathrm{kg})$ on the acute nociceptive response evoked by i.pl. ACR $(10 \mathrm{nmol})$. (H) Effect of IAG $(100 \mathrm{mg} / \mathrm{kg})$ and HC-03 $(100 \mathrm{mg} / \mathrm{kg})$ on the acute nociceptive response evoked by i.pl. $\mathrm{ZnCl}_{2}(10 \mathrm{nmol})$. Values are mean \pm s.e.m of $n=6$ mice for each experimental condition. Veh indicates vehicle of CPS, $\mathrm{NaCl} 0.27 \%, \mathrm{ACR}, \mathrm{ZnCl}_{2}$ and AITC, dash (-) indicates vehicles of IAG, HC03, ibu, CPZ and HC-06. ${ }^{*} P<0.05$ vs. Veh; ${ }^{\S} P<0.05$ vs. CPS or $\mathrm{NaCl} 0.27 \%$, ACR and $\mathrm{ZnCl}_{2},{ }^{\#} P<0.05$ vs. HC-03 and IAG. Oneway ANOVA and post-hoc Bonferroni's test. evoked mechanical allodynia (Fig. 5C). A systemic (intraperitoneal) high dose $(100 \mathrm{mg} / \mathrm{kg})$ of ibuprofen-acyl glucuronide or ibuprofen attenuated the mechanical allodynia induced by carrageenan, but the effect of ibuprofen-acyl glucuronide resulted higher than that of ibuprofen (Fig. 5D, E). The combination of systemic (both intraperitoneal) HC-030031 and ibuprofen increased the inhibitory action of ibuprofen alone, but did not affect the inhibitory response to ibuprofen-acyl glucuronide alone (Fig. 5D, E). Systemic (intraperitoneal) 

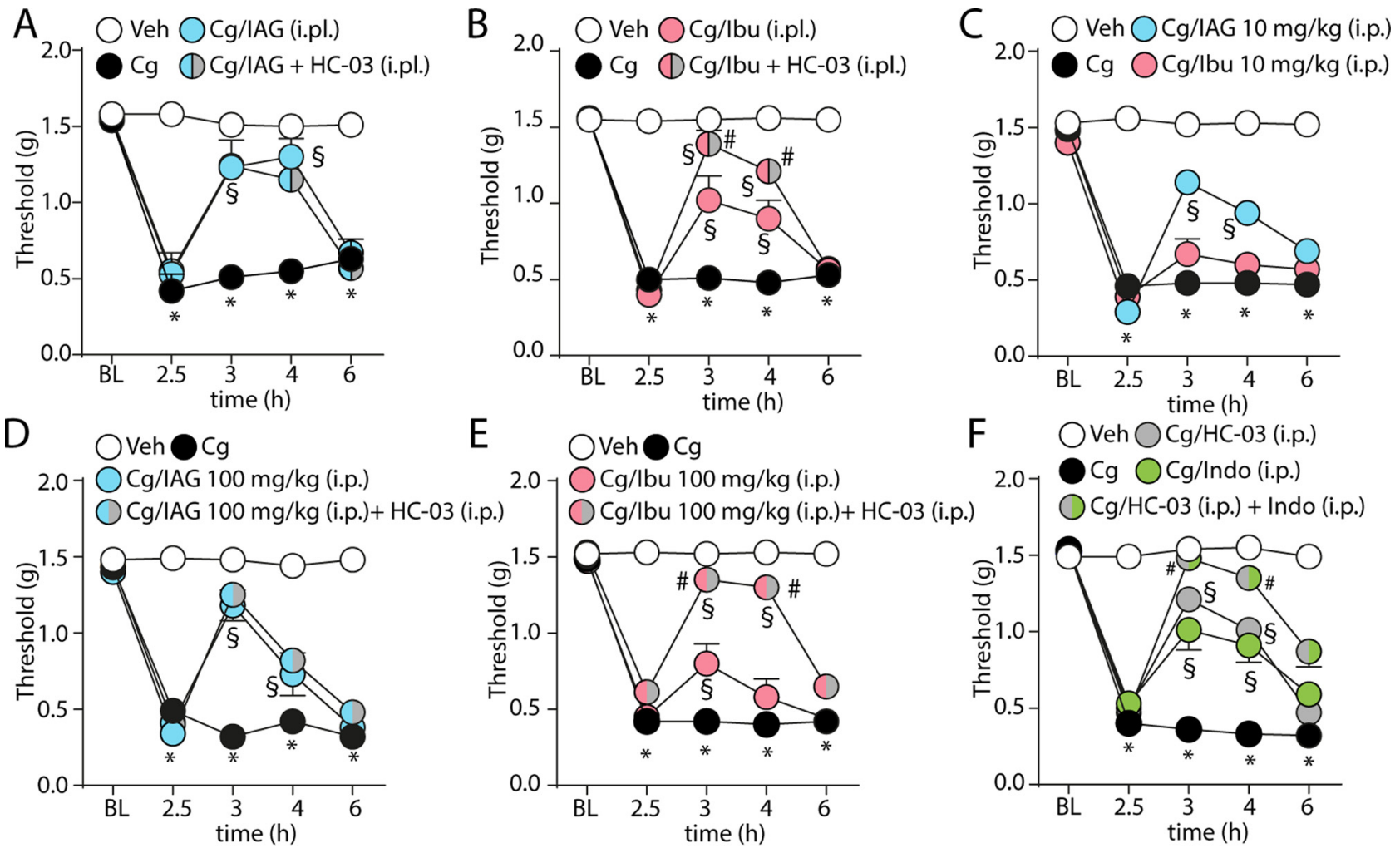

$\mathrm{E}$
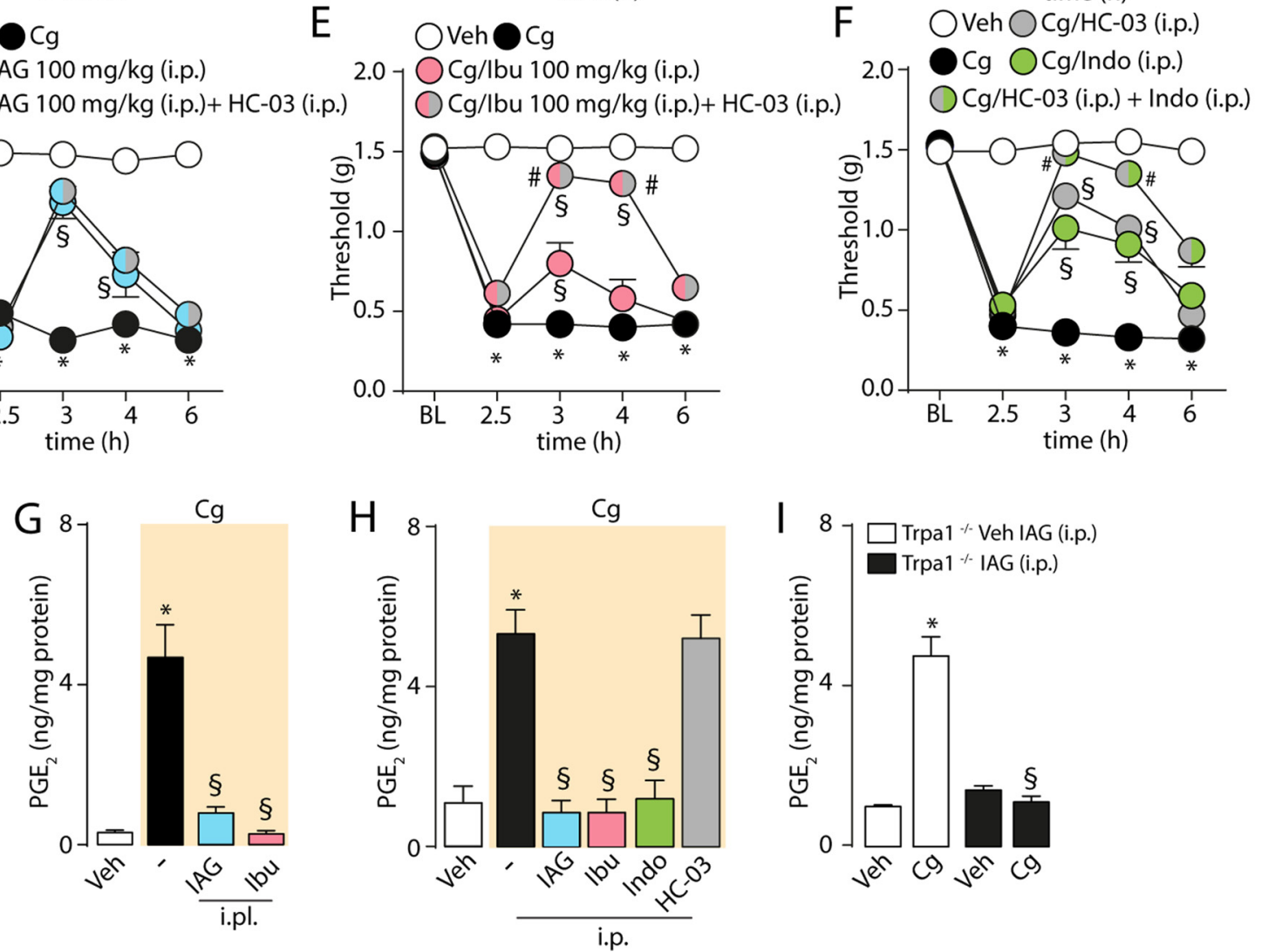

Fig. 5. Ibuprofen-acyl glucuronide produces anti-hyperalgesic effect in the carrageenan model of inflammatory pain. (A,B) Time course of the inhibitory effect of intraplantar (i.pl., $20 \mu \mathrm{l} / \mathrm{paw}$ ) administration of IAG, Ibuprofen (Ibu) (both, $100 \mathrm{nmol}$ ) or of a mixture of IAG and HC-030031 (HC-03) or Ibu and HC-03 (all, $100 \mathrm{nmol}$ ) on the mechanical allodynia evoked by i.pl. carrageenan $(\mathrm{Cg}, 300 \mu \mathrm{g})$ in C57BL/6 J mice. (C-E) Time course of the inhibitory effect of intraperitoneal (i.p.) administration of IAG, Ibu (both, 10 and $100 \mathrm{mg} / \mathrm{kg}$ ) or a combination of IAG $(100 \mathrm{mg} / \mathrm{kg})$ or ibu $(100 \mathrm{mg} / \mathrm{kg})$ and HC-03 (100 mg/kg) on the mechanical allodynia evoked by i.pl. injection of $\mathrm{Cg}(300 \mu \mathrm{g})$ in C57BL/6 J mice. (F) Time course of the inhibitory effect of i.p. HC-03 $(100 \mathrm{mg} / \mathrm{kg})$ and indomethacin (indo, $30 \mathrm{mg} / \mathrm{kg})$ or a combination of both HC-03 $(100 \mathrm{mg} / \mathrm{kg})$ and indo $(30 \mathrm{mg} / \mathrm{kg})$ on the mechanical allodynia evoked by i.pl. injection of Cg ( $300 \mu \mathrm{\mu g})$ in C57BL/6 J mice. (G) PGE 2 levels in paw homogenates measured 180 min after i.pl. $\mathrm{Cg}(300 \mu \mathrm{g})$ in C57BL/ $6 \mathrm{~J}$ mice treated with IAG or Ibu (both, $100 \mathrm{nmol}$, i.pl.). (H) PGE 2 levels in paw homogenates measured $180 \mathrm{~min}$ after i.pl. $\mathrm{Cg}(300 \mu \mathrm{g})$ in C57BL/6 J mice treated with IAG, Ibu, HC-03 (all, $100 \mathrm{mg} / \mathrm{kg}$, i.p.) or indo (30 mg/kg, i.p.). (I) PGE 2 levels in paw homogenates measured $180 \mathrm{~min}$ after i.pl. $\mathrm{Cg}(300 \mu \mathrm{g})$ in $\mathrm{Trpa}^{-/-}$mice after IAG $(100 \mathrm{mg} / \mathrm{kg}$, i.p.). Values are mean $\pm \mathrm{s}$. e.m of $\mathrm{n}=6 \mathrm{mice}$ for each experimental condition. Veh indicates vehicle of $\mathrm{Cg}$, dash (-) indicates vehicles of IAG, Ibu, $\mathrm{HC}-03$ and indo. ${ }^{*} \mathrm{P}<0.05 v s$. Veh; ${ }^{\S} P<0.05 v s$. Cg. ${ }^{\#} P<0.05 v s$. Cg/Ibu or Cg/HC03 or Cg/indo. One- and two-way ANOVA and post-hoc Bonferroni's test.

indomethacin partially inhibited carrageenan-induced mechanical allodynia, and its combination with HC-030031 completely reversed mechanical allodynia (Fig. 5F). Prostaglandin $\mathrm{E}_{2}\left(\mathrm{PGE}_{2}\right)$ assay from paw homogenates of mice receiving carrageenan and treated by local (intraplantar, both $100 \mathrm{nmol}$ ) or systemic (intraperitoneal, both $100 \mathrm{mg}$ / $\mathrm{kg}$ ) ibuprofen-acyl glucuronide or ibuprofen revealed that both drugs produced a similar and complete reduction in the tissue content of $\mathrm{PGE}_{2}$ (Fig. 5G,H). Systemic (intraperitoneal) indomethacin, but not HC030031, reduced $\mathrm{PGE}_{2}$ content in paw homogenates (Fig. 5H). Finally, ibuprofen-acyl glucuronide attenuated carrageenan-evoked $\mathrm{PGE}_{2}$ release in TRPA1 deleted (Trpa1 ${ }^{-/-}$) mice (Fig. 5I). Thus, ibuprofenacyl glucuronide maintains the ability of the parent compound to inhibit COXs.

Formalin injection (intraplantar) into the hind paw of the mouse classically induces a biphasic nociceptive response, with phase I being entirely dependent on TRPA1 [16], whereas phase II involves different mechanisms, including the release of prostanoids. However, during phase II, ongoing diffusion and spread of formalin along TRPA1-expressing nerves may elicit release of a large variety of different mediators, among which prostanoids [54], which may sensitize TRPA1 

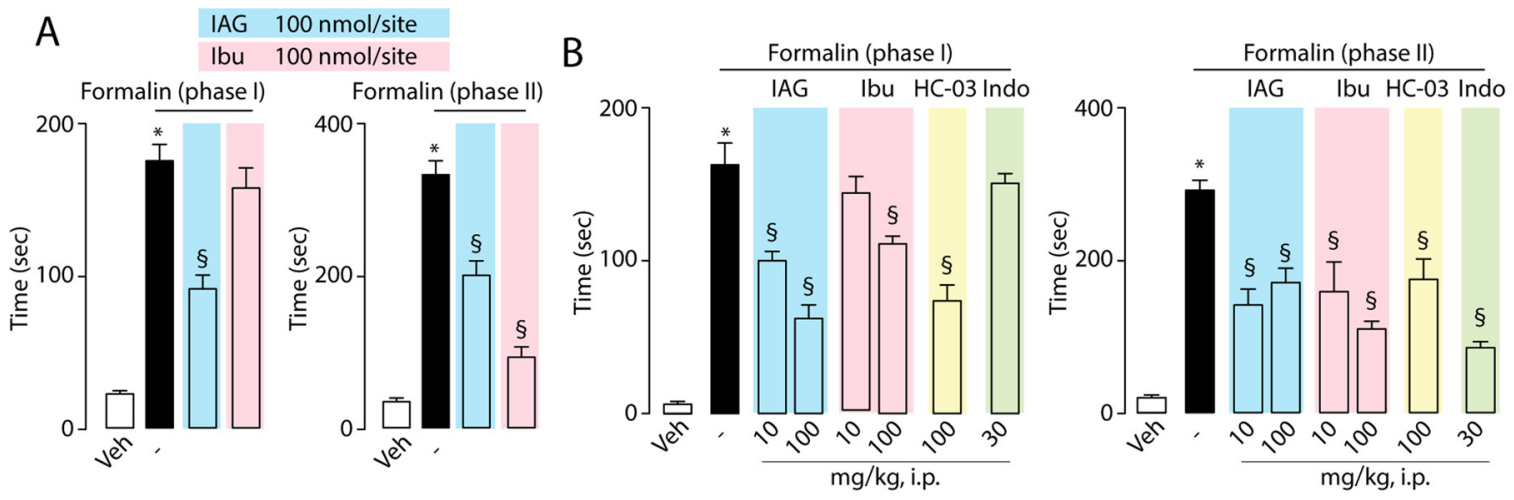

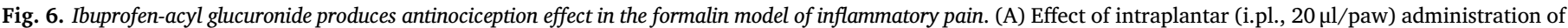

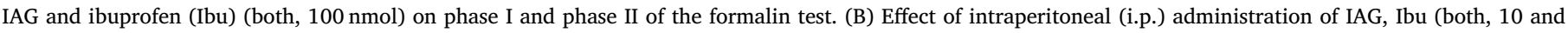

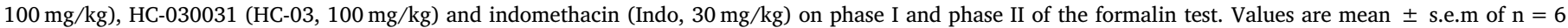

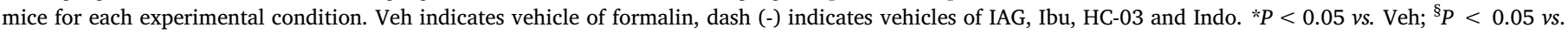
formalin. One-way ANOVA and post-hoc Bonferroni's test.

[55]. Ibuprofen-acyl glucuronide injection (intraplantar) attenuated both phase I and phase II of the response (Fig. 6A). In contrast, ibuprofen failed to affect phase I, but reduced phase II of the formalin test (Fig. 6A). Systemic (intraperitoneal) administration of ibuprofen-acyl glucuronide $(10$ and $100 \mathrm{mg} / \mathrm{kg}$ ) reduced phase I of the formalin test (Fig. 6B). However, only $100 \mathrm{mg} / \mathrm{kg}$, but not $10 \mathrm{mg} / \mathrm{kg}$ (i.p.), of ibuprofen inhibited phase I of the formalin test (Fig. 6B). HC-030031 [16], but not indomethacin [56], inhibited phase I of the formalin test (Fig. 6B), whereas phase II was attenuated by both drugs (Fig. 6B).

\subsection{Ibuprofen-acyl glucuronide reduces interleukin-8 release evoked by TRPA1 stimulation from bronchial epithelial cells}

TRPA1 expressed by various non-neuronal cells of the airways elicits calcium responses and the release of proinflammatory cytokines, including interleukin-8 (IL-8) [25-27]. The calcium responses evoked by AITC in NHBE cells, which constitutively express TRPA1 [27], were attenuated in a concentration-dependent manner by ibuprofen-acyl glucuronide [IC $\mathrm{I0}_{50}, 20(\mathrm{CI}, 13-40) \mu \mathrm{M}$ ] and HC-030031 [IC ${ }_{50}, 10$ (CI, 8-12) $\mu \mathrm{M}$ ] (Fig. 7A-C). Ibuprofen-acyl glucuronide failed to attenuate the rapid calcium responses evoked by acute exposure to hPAR2-AP (Fig. 7C). Exposure to AITC induced a concentration-related release of IL-8 from cultured NHBE cells. This effect was attenuated in the presence of both ibuprofen-acyl glucuronide and HC-030031, but not in the presence of ibuprofen (Fig. 7D). The observation that HC-030031, ibuprofen-acyl glucuronide or ibuprofen did not affect IL-8 release evoked by TNF- $\alpha$ indicated selectivity of ibuprofen-acyl glucuronide and HC-030031 for the AITC-evoked effects (Fig. 7D).

\section{Discussion}

The COX inhibitor ibuprofen is widely used as a first line treatment for the relief of pain and inflammation [2]. Glucuronide metabolites, including those generated from ibuprofen, are generally considered inactive and rapidly excreted compounds [57]. However, acyl glucuronides, undergoing hydrolysis, acyl migration and molecular rearrangement, exhibit chemical reactivity that allow them to covalently bind various macromolecules [57-59]. TRPA1 belongs to such macromolecules that, through Michael addition, undergo nucleophilic attack via specific cysteine/lysine residues [11,12]. Therefore, we hypothesized that, as with various reactive compounds, ibuprofen-acyl glucuronide may react with TRPA1 [11,12]. Our major finding is that ibuprofen-acyl glucuronide, but not its parent compound, ibuprofen, antagonizes the proalgesic TRPA1 channel. This conclusion derives, primarily, from the in vitro pharmacological profile of ibuprofen-acyl glucuronide, which, unlike ibuprofen, selectively inhibits the recombinant and native human TRPA1 and the native rodent channel in nociceptors. Failure of the acyl derivative of indomethacin to affect channel activity underlines the unique ability of ibuprofen-acyl glucuronide to target TRPA1.

Indication that the reactive property of ibuprofen-acyl glucuronide is needed for efficient TRPA1 targeting is based on functional experiments with the mutated form of the human TRPA1 channel, and on docking and molecular dynamic simulations. The mutant hTRPA1-3C/ $\mathrm{K}-\mathrm{Q}$ has the unique property of responding to non-reactive agonists, such as menthol and icilin $[9,11,12]$, but not to reactive agonists, including AITC. In hTRPA1-3C/K-Q expressing cells, ibuprofen-acyl glucuronide did not affect the calcium response evoked by menthol. Thus, the ability of ibuprofen-acyl glucuronide to inhibit TRPA1 depends on the cysteine/lysine residues required for channel activation by electrophilic/reactive agonists. Acyl-glucuronides are known to react by transacylation with nucleophilic residues, leading to the formation of a covalent adduct in which the acyl group, linked to the glucuronide, is transferred to the nucleophilic atom of the residue [57-59]. To explore the interaction between ibuprofen-acyl glucuronide $\mathrm{G}$ and the human TRPA1 channel we performed computational studies, including molecular docking and dynamic simulations, which predicted the formation of covalent adducts between ibuprofen-acyl glucuronide and TRPA1. Computational results with the mutated channel confirm that the inhibitory activity of ibuprofen-acyl glucuronide should be ascribed to its interaction with one of the mutated residues. In vivo results that ibuprofen-acyl glucuronide attenuated nociception evoked by reactive TRPA1 agonists, but not those produced by non-reactive agonists, such as icilin and zinc chloride, further supported the in vitro data and simulation experiments, underlining that chemical reactivity is required for TRPA1 targeting by ibuprofen-acyl glucuronide.

Additional in vivo data strengthen the conclusion obtained from in vitro findings. Local injection of ibuprofen-acyl glucuronide in the mouse hind paw prevented acute nociception elicited by local administration of the reactive TRPA1 agonists, AITC and acrolein, but was ineffective against TRPV1 or TRPV4 agonists, indicating selectivity. Notably, local injection of ibuprofen in the mouse hind paw did not affect AITC or acrolein-evoked nociception. It is possible that following i.pl. ibuprofen no ibuprofen-acyl glucuronide is generated locally, and the action of TRPA1 agonists remains unopposed. However, about $10-15 \%$ of systemic ibuprofen is converted into ibuprofen-acyl glucuronide [28]. Thus, liver metabolism of a high dose of ibuprofen may produce ibuprofen-acyl glucuronide levels such as to guarantee a local concentration sufficient for inhibiting TRPA1. This hypothesis is supported by the observation that a high dose of systemic ibuprofen produced a partial attenuation of the nociception evoked by AITC.

Other NSAIDs, which derive from propionic acid, are known to 
A
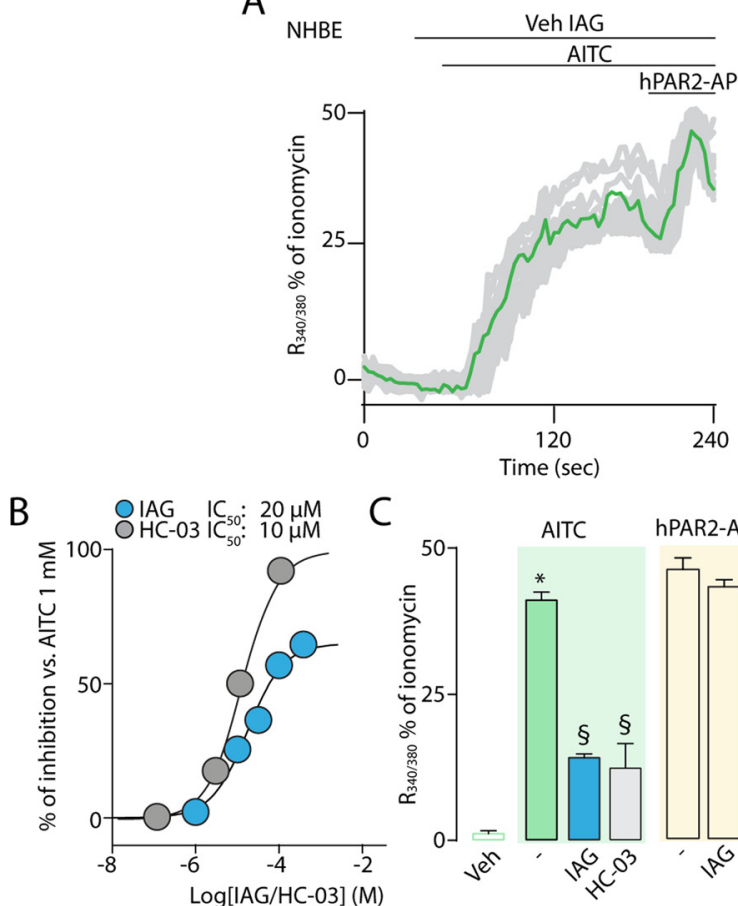

C

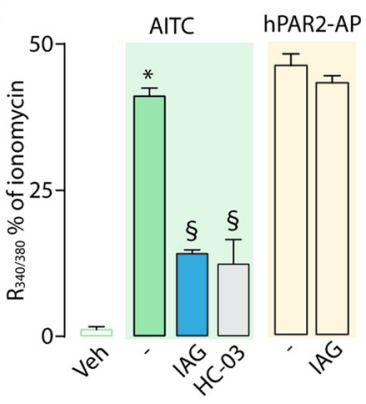

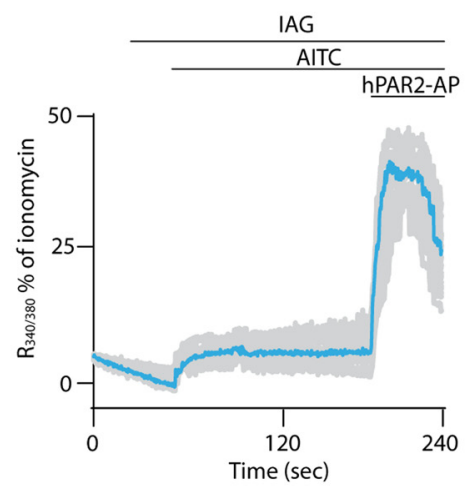

$\mathrm{D}$
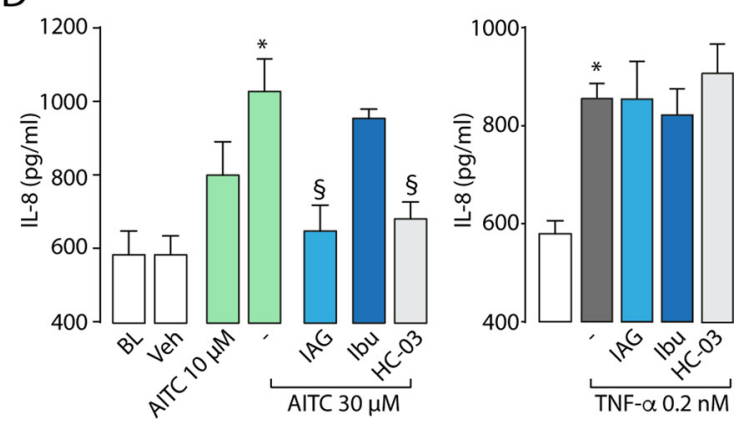

Fig. 7. Ibuprofen-acyl glucuronide antagonizes human native TRPA1 in NHBE cells reducing the IL-8 release. (A) Typical traces of the effect of pre-exposure (10 min) to Veh (vehicle) IAG/IAG $(100 \mu \mathrm{M})$ on the calcium response evoked by AITC $(1 \mathrm{mM})$ and the hPAR2-AP $(100 \mu \mathrm{M})$ in NHBE cells. (B,C) Concentration-response curves and pooled data of the inhibitory effect of IAG $(0.1-1000 \mu \mathrm{M})$ and HC-030031 (HC-03, $0.1-1000 \mu \mathrm{M})$ on the calcium response evoked by AITC (1 mM) in NHBE cells. (D) IL-8 release from NHBE cells exposed to AITC $(10$ and $30 \mu \mathrm{M})$ or TNF- $\alpha(0.2 \mathrm{nM})$ and pretreated with IAG and ibuprofen (Ibu) (both, $100 \mu \mathrm{M})$ and HC-03 (30 $\mu \mathrm{M})$. Values are mean \pm s.e.m. of $\mathrm{n}>25$ cells from at least 3 different experiments for each condition or at least 3 independent experiments. Veh indicates vehicle of AITC and TNF- $\alpha$, dash (-) indicates vehicles of IAG, Ibu and HC-03. ${ }^{*} P<0.05 v s$. Veh; ${ }^{\S} P<0.05$ v. AITC. One-way ANOVA and post-hoc Bonferroni's test.

generate acyl glucuronides through hepatic metabolism. These acyl derivatives could potentially possess anti-TRPA1 properties similar to those of ibuprofen-acyl glucuronide. However, acyl glucuronidation does not warrant per se that the metabolites possess the chemical requirements for effective TRPA1 antagonism. For example, we failed to detect any effect of the acyl derivative of indomethacin, acyl- $\beta$-D-glucuronide, in antagonizing AITC evoked calcium response in vitro, and systemic indomethacin pretreatment did not affect the acute nociception of phase I of the formalin test.

The analgesic action of ibuprofen derives from its ability to inhibit COXs, and the ensuing blockade of prostaglandin generation [3,4]. This feature also justifies the anti-inflammatory activity of ibuprofen. While we provided evidence that ibuprofen-acyl glucuronide targets TRPA1, we wondered whether it maintains the ability of the parent drug to inhibit COXs. We also wondered whether ibuprofen-acyl glucuronide ability to inhibit TRPA1 may exert anti-inflammatory activity in an ibuprofen-independent manner. Carrageenan injection in rodent paw evokes inflammation and prolonged allodynia that are in part mediated by prostaglandins and in part by TRPA1 $[17,18,40,60]$. When allodynia was analyzed, local (intraplantar) ibuprofen-acyl glucuronide elicited a more robust inhibitory effect than that of an identical dose of ibuprofen, and the combination with HC-030031 potentiated inhibition by ibuprofen, but not that by ibuprofen-acyl glucuronide. Because both ibuprofen-acyl glucuronide and ibuprofen ablated $\mathrm{PGE}_{2}$ levels it is possible that the effect of locally administered ibuprofen-acyl glucuronide is due to both COX inhibition and TRPA1 antagonism, whereas locally administered ibuprofen solely inhibits COXs.

The study of systemic administered drugs strengthens this hypothesis. A low dose of ibuprofen-acyl glucuronide, but not ibuprofen, attenuated carrageenan-evoked allodynia. A high dose of ibuprofen-acyl glucuronide or ibuprofen completely reversed or partially inhibited allodynia, respectively. Furthermore, the combination of the high dose of ibuprofen and HC-030031 potentiated the effect of ibuprofen alone. Similar results were obtained with indomethacin (its metabolite, acyl- $\beta$ D-glucuronide-indomethacin, does not target TRPA1) alone or in combination with HC-030031. Thus, TRPA1 stimulation by endogenous agonists generated by carrageenan-evoked inflammation cannot be completely surmounted by the amount of ibuprofen-acyl glucuronide generated by systemic metabolism of $100 \mathrm{mg} / \mathrm{kg}$ ibuprofen. The observation that both systemic ibuprofen and ibuprofen-acyl glucuronide completely inhibited $\mathrm{PGE}_{2}$ generation evoked by carrageen, indicates that the metabolite maintains the COX inhibitory activity of the parent drug, and justify the complete attenuation of carrageenan-evoked allodynia by ibuprofen-acyl glucuronide which may simultaneously inhibit COXs and TRPA1. TRPA1 has been reported to contribute to inflammation by different pathways, including the release of proinflammatory cytokines, such as IL-8 $[25,26]$. The present in vitro observation that ibuprofen-acyl glucuronide, but not ibuprofen, attenuates the TRPA1-dependent ability of NHBE cells to release IL-8 underlines the contribution of the COX-independent anti-inflammatory activity of the metabolite.

Our findings add new insights into the antinociceptive/anti-hyperalgesic and anti-inflammatory activity of ibuprofen which, in addition to COX inhibition, attenuates TRPA1 activity via ibuprofen-acyl glucuronide generation. This novel mechanism of ibuprofen/ibuprofenacyl glucuronide indirectly underlines the TRPA1 contribution to acute nociception and delayed allodynia in various models of inflammatory pain. Further studies are needed to establish whether TRPA1 antagonism by ibuprofen-acyl glucuronide contributes to the therapeutic effect of ibuprofen in pain and inflammation in humans, and whether ibuprofen-acyl glucuronide may have an efficacy and safety profile different from its parent drug. 


\section{Funding}

This study was supported by Ministry for University and Scientific Research (MiUR) Rome, Italy Grants PRIN 201532AHAE_003 (P.G.) and Associazione Italiana per la Ricerca sul Cancro (AIRC, IG 19247) and Fondazione Cassa di Risparmio di Firenze, Italy (R.N.).

\section{Acknowledgments}

We thank A.H. Morice (University of Hull, UK) for the hTRPA1HEK293 and hTRPA1/V1-HEK293 cells, M.J. Gunthorpe (GlaxoSmithKline, UK) for the hTRPV1-HEK293 cells, N.W. Bunnett (Monash Institute of Pharmaceutical Sciences, Australia) for the hTRPV4-HEK293 cells, D. Julius (UCSF, CA USA) for the human TRPA1 wild type and human TRPA1 mutant (C619S, C639S, C663S, K708Q) cDNAs, and G. Cirino (University of Naples, Italy) for PAR2 selective agonist, SLIGKV-NH $\mathrm{N}_{2}$. R.P. is fully employed at Chiesi Farmaceutici SpA, Parma, Italy. The other authors declare no competing financial interests.

\section{References}

[1] N.M. Davies, Clinical pharmacokinetics of ibuprofen. The first 30 years, Clin. Pharmacokinet. 34 (2) (1998) 101-154.

[2] K.D. Rainsford, Ibuprofen: pharmacology, efficacy and safety, Inflammopharmacology 17 (6) (2009) 275-342.

[3] E.M. Boneberg, M.H. Zou, V. Ullrich, Inhibition of cyclooxygenase-1 and -2 by R(-)and S(+)-ibuprofen, J. Clin. Pharmacol. 36 (12 Suppl) (1996) 16S-19S.

[4] J.K. Gierse, C.M. Koboldt, M.C. Walker, K. Seibert, P.C. Isakson, Kinetic basis for selective inhibition of cyclo-oxygenases, Biochem. J. 339 (Pt 3) (1999) 607-614.

[5] M. Bandell, G.M. Story, S.W. Hwang, V. Viswanath, S.R. Eid, M.J. Petrus, T.J. Earley, A. Patapoutian, Noxious cold ion channel TRPA1 is activated by pungent compounds and bradykinin, Neuron 41 (6) (2004) 849-857.

[6] Y. Sawada, H. Hosokawa, K. Matsumura, S. Kobayashi, Activation of transient receptor potential ankyrin 1 by hydrogen peroxide, Eur. J. Neurosci. 27 (5) (2008) $1131-1142$.

[7] D.M. Bautista, S.E. Jordt, T. Nikai, P.R. Tsuruda, A.J. Read, J. Poblete, E.N. Yamoah, A.I. Basbaum, D. Julius, TRPA1 mediates the inflammatory actions of environmental irritants and proalgesic agents, Cell 124 (6) (2006) 1269-1282.

[8] T.E. Taylor-Clark, S. Ghatta, W. Bettner, B.J. Undem, Nitrooleic acid, an endogenous product of nitrative stress, activates nociceptive sensory nerves via the direct activation of TRPA1, Mol. Pharmacol. 75 (4) (2009) 820-829.

[9] M. Trevisani, J. Siemens, S. Materazzi, D.M. Bautista, R. Nassini, B. Campi, N. Imamachi, E. Andre, R. Patacchini, G.S. Cottrell, R. Gatti, A.I. Basbaum, N.W. Bunnett, D. Julius, P. Geppetti, 4-Hydroxynonenal, an endogenous aldehyde, causes pain and neurogenic inflammation through activation of the irritant receptor TRPA1, Proc. Natl. Acad. Sci. U. S. A. 104 (33) (2007) 13519-13524.

[10] E. Andre, B. Campi, S. Materazzi, M. Trevisani, S. Amadesi, D. Massi, C. Creminon, N. Vaksman, R. Nassini, M. Civelli, P.G. Baraldi, D.P. Poole, N.W. Bunnett, P. Geppetti, R. Patacchini, Cigarette smoke-induced neurogenic inflammation is mediated by alpha,beta-unsaturated aldehydes and the TRPA1 receptor in rodents, J. Clin. Invest. 118 (7) (2008) 2574-2582.

[11] A. Hinman, H.H. Chuang, D.M. Bautista, D. Julius, TRP channel activation by reversible covalent modification, Proc. Natl. Acad. Sci. U. S. A. 103 (51) (2006) 19564-19568.

[12] L.J. Macpherson, A.E. Dubin, M.J. Evans, F. Marr, P.G. Schultz, B.F. Cravatt, A. Patapoutian, Noxious compounds activate TRPA1 ion channels through covalent modification of cysteines, Nature 445 (7127) (2007) 541-545.

[13] E.L. Andrade, F.C. Meotti, J.B. Calixto, TRPA1 antagonists as potential analgesic drugs, Pharmacol. Ther. 133 (2) (2012) 189-204.

[14] B. Nilius, G. Owsianik, T. Voets, J.A. Peters, Transient receptor potential cation channels in disease, Physiol. Rev. 87 (1) (2007) 165-217.

[15] R. Nassini, S. Materazzi, S. Benemei, P. Geppetti, The TRPA1 channel in inflammatory and neuropathic pain and migraine, Rev. Physiol. Biochem. Pharmacol. 176 (2014) 1-43.

[16] C.R. McNamara, J. Mandel-Brehm, D.M. Bautista, J. Siemens, K. L. Deranian, M. Zhao, N.J. Hayward, J.A. Chong, D. Julius, M.M. Moran, C.M. Fanger, TRPA1 mediates formalin-induced pain, Proc. Natl. Acad. Sci. U. S. A. 104 (33) (2007) $13525-13530$

[17] I.J. Bonet, L. Fischer, C.A. Parada, C.H. Tambeli, The role of transient receptor potential A 1 (TRPA1) in the development and maintenance of carrageenan-induced hyperalgesia, Neuropharmacology 65 (2013) 206-212.

[18] L.J. Moilanen, M. Laavola, M. Kukkonen, R. Korhonen, T. Leppanen, E. D. Hogestatt, P.M. Zygmunt, R.M. Nieminen, E. Moilanen, TRPA1 contributes to the acute inflammatory response and mediates carrageenan-induced paw edema in the mouse, Sci. Rep. 2 (380) (2012) 380.

[19] S.R. Eid, E.D. Crown, E.L. Moore, H.A. Liang, K.C. Choong, S. Dima, D.A. Henze, S.A. Kane, Urban MO. HC-030031, a TRPA1 selective antagonist, attenuates inflammatory- and neuropathy-induced mechanical hypersensitivity, Mol. Pain 4 (48)
(2008) 48.

[20] H. Wei, M.M. Hamalainen, M. Saarnilehto, A. Koivisto, A. Pertovaara, Attenuation of mechanical hypersensitivity by an antagonist of the TRPA1 ion channel in diabetic animals, Anesthesiology 111 (1) (2009) 147-154.

[21] F. De Logu, R. Nassini, S. Materazzi, M. Carvalho Goncalves, D. Nosi, D. Ross Degl'Innocenti, I.M. Marone, J. Ferreira, S. Li Puma, S. Benemei, G. Trevisan, Monteiro Souza, D. de Araujo, R. Patacchini, N.W. Bunnett, P. Geppetti, Schwann cell TRPA1 mediates neuroinflammation that sustains macrophage-dependent neuropathic pain in mice, Nat. Commun. 8 (1) (2017) 1887.

[22] R. Nassini, M. Gees, S. Harrison, G. De Siena, S. Materazzi, N. Moretto, P. Failli, D. Preti, N. Marchetti, A. Cavazzini, F. Mancini, P. Pedretti, B. Nilius, R. Patacchini, P. Geppetti, Oxaliplatin elicits mechanical and cold allodynia in rodents via TRPA1 receptor stimulation, Pain 152 (7) (2011) 1621-1631.

[23] G. Trevisan, S. Materazzi, C. Fusi, A. Altomare, G. Aldini, M. Lodovici, R. Patacchini, P. Geppetti, R. Nassini, Novel therapeutic strategy to prevent chemotherapy-induced persistent sensory neuropathy by TRPA1 blockade, Cancer Res. 73 (10) (2013) 3120-3131.

[24] M.M. Moran, TRP channels as potential drug targets, Annu. Rev. Pharmacol. Toxicol. 58 (2018) 309-330.

[25] R. Nassini, P. Pedretti, N. Moretto, C. Fusi, C. Carnini, F. Facchinetti, A.R. Viscomi, A.R. Pisano, S. Stokesberry, C. Brunmark, N. Svitacheva, L. McGarvey, R. Patacchini, A.B. Damholt, P. Geppetti, S. Materazzi, Transient receptor potential ankyrin 1 channel localized to non-neuronal airway cells promotes non-neurogenic inflammation, PLoS One 7 (8) (2012) e42454.

[26] I. Mukhopadhyay, P. Gomes, S. Aranake, M. Shetty, P. Karnik, M. Damle, S. Kuruganti, S. Thorat, N. Khairatkar-Joshi, Expression of functional TRPA1 receptor on human lung fibroblast and epithelial cells, J. Recept. Signal Transduct. Res. 31 (5) (2011) 350-358.

[27] A.H. Lin, M.H. Liu, H.K. Ko, D.W. Perng, T.S. Lee, Y.R. Kou, Lung Epithelial TRPA1 Transduces the Extracellular ROS into Transcriptional Regulation of Lung Inflammation Induced by Cigarette Smoke: The Role of Influxed $\mathrm{Ca}(2)(+)$, Mediators Inflamm. 2015 (10) (2015) 148367.

[28] A.C. Rudy, P.M. Knight, D.C. Brater, S.D. Hall, Stereoselective metabolism of ibuprofen in humans: administration of R-, S- and racemic ibuprofen, J. Pharmacol. Exp. Ther. 259 (3) (1991) 1133-1139.

[29] D.R. Kepp, U.G. Sidelmann, S.H. Hansen, Isolation and characterization of major phase I and II metabolites of ibuprofen, Pharm. Res. 14 (5) (1997) 676-680.

[30] M. Castillo, Y.W. Lam, M.A. Dooley, E. Stahl, P.C. Smith, Disposition and covalen binding of ibuprofen and its acyl glucuronide in the elderly, Clin. Pharmacol. Ther. 57 (6) (1995) 636-644.

[31] B.C. Sallustio, L. Sabordo, A.M. Evans, R.L. Nation, Hepatic disposition of electrophilic acyl glucuronide conjugates, Curr. Drug Metab. 1 (2) (2000) 163-180.

[32] K.Y. Kwan, A.J. Allchorne, M.A. Vollrath, A.P. Christensen, D.S. Zhang, C.J. Woolf, D.P. Corey, TRPA1 contributes to cold, mechanical, and chemical nociception but is not essential for hair-cell transduction, Neuron 50 (2) (2006) 277-289.

[33] C. Kilkenny, W.J. Browne, I.C. Cuthill, M. Emerson, D.G. Altman, Improving bioscience research reporting: the ARRIVE guidelines for reporting animal research, J. Pharmacol. Pharmacother. 1 (2) (2010) 94-99.

[34] F. Faul, E. Erdfelder, A. Buchner, A.G. Lang, Statistical power analyses using $G^{*}$ Power 3.1: tests for correlation and regression analyses, Behav. Res. Methods 41 (4) (2009) 1149-1160.

[35] S. Materazzi, C. Fusi, S. Benemei, P. Pedretti, R. Patacchini, B. Nilius, J. Prenen, C. Creminon, P. Geppetti, R. Nassini, TRPA1 and TRPV4 mediate paclitaxel-induced peripheral neuropathy in mice via a glutathione-sensitive mechanism, Pflugers Arch. 463 (4) (2012) 561-569.

[36] D.M. Bautista, P. Movahed, A. Hinman, H.E. Axelsson, O. Sterner, E.D. Hogestatt, D. Julius, S.E. Jordt, P.M. Zygmunt, Pungent products from garlic activate the sensory ion channel TRPA1, Proc. Natl. Acad. Sci. U. S. A. 102 (34) (2005) 12248-12252.

[37] M. Trevisani, D. Smart, M.J. Gunthorpe, M. Tognetto, M. Barbieri, B. Campi, S. Amadesi, J. Gray, J.C. Jerman, S.J. Brough, D. Owen, G.D. Smith, A.D. Randall, S. Harrison, A. Bianchi, J.B. Davis, P. Geppetti, Ethanol elicits and potentiates nociceptor responses via the vanilloid receptor-1, Nat. Neurosci. 5 (6) (2002) 546-551.

[38] A.D. Grant, G.S. Cottrell, S. Amadesi, M. Trevisani, P. Nicoletti, S. Materazzi, C. Altier, N. Cenac, G.W. Zamponi, F. Bautista-Cruz, C.B. Lopez, E.K. Joseph, J.D. Levine, W. Liedtke, S. Vanner, N. Vergnolle, P. Geppetti, N.W. Bunnett, Protease-activated receptor 2 sensitizes the transient receptor potential vanilloid 4 ion channel to cause mechanical hyperalgesia in mice, J. Physiol. 578 (Pt 3) (2007) 715-733.

[39] L.R. Sadofsky, K.T. Sreekrishna, Y. Lin, R. Schinaman, K. Gorka, Y. Mantri, J.C. Haught, T.G. Huggins, R.J. Isfort, C.C. Bascom, A.H. Morice, Unique responses are observed in transient receptor potential ankyrin 1 and vanilloid 1 (TRPA1 and TRPV1) co-expressing cells, Cells 3 (2) (2014) 616-626.

[40] R. Nassini, C. Fusi, S. Materazzi, E. Coppi, T. Tuccinardi, I.M. Marone, F. De Logu, D. Preti, R. Tonello, A. Chiarugi, R. Patacchini, P. Geppetti, S. Benemei, The TRPA1 channel mediates the analgesic action of dipyrone and pyrazolone derivatives, $\mathrm{Br}$. J. Pharmacol. 172 (13) (2015) 3397-3411.

[41] R. Tonello, C. Fusi, S. Materazzi, I.M. Marone, F. De Logu, S. Benemei, M.C. Goncalves, E. Coppi, C.J. Castro-Junior, M.V. Gomez, P. Geppetti, J. Ferreira, R. Nassini, The peptide Phalphalbeta, from spider venom, acts as a TRPA1 channel antagonist with antinociceptive effects in mice, Br. J. Pharmacol. 174 (1) (2017) $57-69$.

[42] W. Everaerts, X. Zhen, D. Ghosh, J. Vriens, T. Gevaert, J.P. Gilbert, N.J. Hayward, C.R. McNamara, F. Xue, M.M. Moran, T. Strassmaier, E. Uykal, G. Owsianik, R. Vennekens, D. De Ridder, B. Nilius, C.M. Fanger, T. Voets, Inhibition of the cation 
channel TRPV4 improves bladder function in mice and rats with cyclophosphamideinduced cystitis, Proc. Natl. Acad. Sci. U. S. A. 107 (44) (2010) 19084-19089.

[43] S.R. Chaplan, F.W. Bach, J.W. Pogrel, J.M. Chung, T.L. Yaksh, Quantitative assessment of tactile allodynia in the rat paw, J. Neurosci. Methods 53 (1) (1994) 55-63.

[44] W.J. Dixon, Efficient analysis of experimental observations, Annu. Rev. Pharmacol. Toxicol. 20 (1980) 441-462.

[45] Y. Ma, Y. Li, X. Li, Y. Wu, Anti-inflammatory effects of 4-methylcyclopentadecanone on edema models in mice, Int. J. Mol. Sci. 14 (12) (2013) 23980-23992.

[46] C.E. Paulsen, J.P. Armache, Y. Gao, Y. Cheng, D. Julius, Structure of the TRPA1 ion channel suggests regulatory mechanisms, Nature 525 (7570) (2015) 552.

[47] N. Eswar, B. Webb, M.A. Marti-Renom, M.S. Madhusudhan, D. Eramian, M.Y. Shen, U. Pieper, A. Sali, Comparative protein structure modeling using Modeller, Curr. Protoc. Bioinformatics 5 (2006) Chapter 5 Unit-5 6.

[48] W. Humphrey, A. Dalke, K. Schulten, VMD: visual molecular dynamics, J. Mol. Graph. 14 (1) (1996) 33-38 27-38.

[49] C.J. Dickson, B.D. Madej, A.A. Skjevik, R.M. Betz, K. Teigen, I.R. Gould, Walker RC. Lipid14: the amber lipid force field, J. Chem. Theory Comput. 10 (2) (2014) 865-879.

[50] M.L. Verdonk, J.C. Cole, M.J. Hartshorn, C.W. Murray, R.D. Taylor, Improved protein-ligand docking using GOLD, Proteins 52 (4) (2003) 609-623.

[51] D.D. McKemy, W.M. Neuhausser, D. Julius, Identification of a cold receptor reveals a general role for TRP channels in thermosensation, Nature 416 (6876) (2002) $52-58$.

[52] H. Hu, M. Bandell, M.J. Petrus, M.X. Zhu, A. Patapoutian, Zinc activates damagesensing TRPA1 ion channels, Nat. Chem. Biol. 5 (3) (2009) 183-190.
[53] D. Jaquemar, T. Schenker, B. Trueb, An ankyrin-like protein with transmembrane domains is specifically lost after oncogenic transformation of human fibroblasts, $\mathrm{J}$ Biol. Chem. 274 (11) (1999) 7325-7333.

[54] M.J. Fischer, K.J. Soller, S.K. Sauer, J. Kalucka, G. Veglia, P.W. Reeh, Formalin evokes calcium transients from the endoplasmatic reticulum, PLoS One 10 (4) (2015) e0123762.

[55] M.C. Dall'Acqua, I.J. Bonet, A.R. Zampronio, C.H. Tambeli, C.A. Parada, L. Fischer, The contribution of transient receptor potential ankyrin 1 (TRPA1) to the in vivo nociceptive effects of prostaglandin E(2), Life Sci. 105 (1-2) (2014) 7-13.

[56] A.B. Malmberg, T.L. Yaksh, Antinociceptive actions of spinal nonsteroidal anti-inflammatory agents on the formalin test in the rat, J. Pharmacol. Exp. Ther. 263 (1) (1992) 136-146.

[57] H.K. Kroemer, U. Klotz, Glucuronidation of drugs. A re-evaluation of the pharmacological significance of the conjugates and modulating factors, Clin. Pharmacokinet. 23 (4) (1992) 292-310.

[58] E.M. Faed, Properties of acyl glucuronides: implications for studies of the pharmacokinetics and metabolism of acidic drugs, Drug Metab. Rev. 15 (5-6) (1984) 1213-1249.

[59] H. Spahn-Langguth, L.Z. Benet, Acyl glucuronides revisited: is the glucuronidation process a toxification as well as a detoxification mechanism? Drug Metab. Rev. 24 (1) (1992) 5-47.

[60] N.A. El-Shitany, E.A. El-Bastawissy, K. El-desoky, Ellagic acid protects against carrageenan-induced acute inflammation through inhibition of nuclear factor kappa $\mathrm{B}$, inducible cyclooxygenase and proinflammatory cytokines and enhancement of interleukin-10 via an antioxidant mechanism, Int. Immunopharmacol. 19 (2) (2014) 290-299. 